\title{
Aerodynamics of a Gulfstream G550 Nose Landing Gear Model
}

\author{
Dan H. Neuhart ${ }^{*}$, Mehdi R. Khorrami ${ }^{\dagger}$, and Meelan M. Choudhari ${ }^{\dagger}$ \\ NASA Langley Research Center, Hampton, Virginia, 23681
}

\begin{abstract}
In this paper we discuss detailed steady and unsteady aerodynamic measurements of a Gulfstream G550 nose landing gear model. The quarter-scale, high-fidelity model includes part of the lower fuselage and the gear cavity. The full model configuration allowed for removal of various gear components (e.g. light cluster, steering mechanism, hydraulic lines, etc.) in order to document their effects on the local flow field. The measurements were conducted at a Reynolds number of $7.3 \times 10^{4}$ based on the shock strut (piston) diameter and a freestream Mach number of 0.166. Additional data were also collected at lower Mach numbers of 0.12 and 0.145 and correspondingly lower Reynolds numbers. The boundary layer on the piston was tripped to enable turbulent flow separation, so as to better mimic the conditions encountered during flight. Steady surface pressures were gathered from an extensive number of static ports on the wheels, door, fuselage, and within the gear cavity. To better understand the resultant flow interactions between gear components, surface pressure fluctuations were collected via sixteen dynamic pressure sensors strategically placed on various subcomponents of the gear. Fifteen of the transducers were flush mounted on the gear surface at fixed locations, while the remaining one was a mobile transducer that could be placed at numerous varying locations. The measured surface pressure spectra are mainly broadband in nature, lacking any local peaks associated with coherent vortex shedding. This finding is in agreement with off-surface flow measurements using PIV that revealed the flow field to be a collection of separated shear layers without any dominant vortex shedding processes.
\end{abstract}

Nomenclature

$$
\begin{array}{ll}
C_{P} & =\text { pressure coefficient, } \frac{p-p_{\infty}}{q_{\infty}} \\
C_{P^{\prime} r m s} & =\text { fluctuating pressure coefficient, } \frac{p_{r m s}^{\prime}}{q_{\infty}} \\
p_{r m s}^{\prime} & =\text { root-mean-square pressure fluctuation } \\
p & =\text { instantaneous pressure measured on model surface } \\
p_{\infty} & =\text { free-stream static pressure } \\
q_{\infty} & =\text { free-stream dynamic pressure } \\
\mathrm{s} & =\text { radial surface coordinate on port wheel } \\
\mathrm{TKE} & =\text { turbulent kinetic energy, } \frac{1}{2}\left(\left(u_{r m s}^{\prime}\right)^{2}+\left(v_{r m s}^{\prime}\right)^{2}\right) \\
\mathrm{u}_{\text {rms }}^{\prime} & =\text { root-mean-square streamwise velocity fluctuation } \\
\mathrm{v}_{\text {rms }} & =\text { root-mean-square lateral velocity fluctuation } \\
X & =\text { streamwise coordinate } \\
Y & =\text { lateral coordinate } \\
Z & =\text { vertical coordinate }
\end{array}
$$

\footnotetext{
${ }^{*}$ Research Engineer, Flow Physics and Control Branch

${ }^{\dagger}$ Research Engineer, Computational AeroSciences Branch, Associate Fellow, AIAA
} 


\section{Introduction}

Undercarriage structures are major contributors to the component of airframe noise that is radiated to the ground during aircraft approach and landing at the airport. For smaller transports or the regional jet class of aircraft, both the main gear and the nose gear are equally important sources of airframe noise. ${ }^{1,2}$ For medium and larger size civil transports, on the other hand, the main landing gear is the more dominant source because of its more complex bogie system as compared to the nose landing gear ${ }^{3-5}$. For this reason, the vast majority of the previous studies targeting both model-scale and full-scale landing gear noise were directed at main gears having four or more wheels. ${ }^{6-11}$ Thus far, the aeroacoustic characteristics of nose landing gears, i.e., a single pair of wheels, have received little attention. To partially remedy this shortcoming, the present study focuses on the aeroacoustic characteristics of a nose landing gear. This work represents an important aspect of a partnership effort between NASA and Gulfstream Aerospace Corporation that is directed at understanding, and ultimately predicting, the prominent sources of airframe noise.

The main thrust of the NASA-Gulfstream partnership is targeted at acquiring a comprehensive aeroacoustic database on the principal sources of airframe noise. Availability of such a database is a vital step toward improving our understanding of the prevalent sound generation mechanisms so that viable methodologies for noise abatement can be developed. Advances in prediction methodologies for airframe noise require high-fidelity numerical simulations in conjunction with high-quality experimental data to guide the development and validation of physics-based theoretical/numerical models. Increasingly, computational fluid dynamic (CFD) and computational aeroacoustic (CAA) tools are being utilized to provide greater understanding of, and to help solve, complex airframe noise problems. Within the last decade, application of computational simulations to landing gear configurations has successfully migrated from consideration of relatively simple gear geometries ${ }^{12-16}$ to flight-ready full-scale nose gear configurations $^{17-19}$ A universal shortcoming of these simulations is the lack of proper validation of the computed results, which is a direct consequence of the unavailability of comprehensive aeroacoustic measurements for realistic nose landing gear geometries. It is envisioned that the database collected from these tests will be of great value during the development and benchmarking of physics-based prediction models at any level of fidelity.

The NASA-Gulfstream research partnership consists of several phases involving both full-scale flight and groundbased model-scale tests. The initial flight test (Ref. 2) conducted in October 2006 identified the dominant airframe noise sources associated with the Gulfstream G550 aircraft. A carefully planned test matrix helped isolate both individual components of noise (e.g., flaps, main landing gear, nose landing gear, etc.) and the noise associated with component interaction (viz., gear-flap interaction). The set of experiments discussed here is part of the next phase of this joint effort, which is focused on conducting comprehensive aeroacoustic measurements using a model-scale G550 nose gear as a test bed. The extensive steady and unsteady aerodynamic measurements, conducted at NASA Langley Research Center (LaRC), are presented in this paper. The acoustic measurements, acquired in the open-jet anechoic tunnel at the University of Florida, are discussed in a companion paper. ${ }^{20}$

\section{Experimental Apparatus and Techniques}

\section{A. Test Facility}

The experiment was conducted in the NASA-LaRC Basic Aerodynamics Research Tunnel (BART). This tunnel is a subsonic, atmospheric wind tunnel used to investigate the fundamental characteristics of complex flow fields and to acquire detailed data for the development and validation of CFD models and methods. The tunnel has a closed test section with a height of 28 inches $(0.711 \mathrm{~m})$, a width of 40 inches $(1.016 \mathrm{~m})$, and a length of 120 inches $(3.048 \mathrm{~m})$. The test was run at a freestream Mach number of 0.166 , which translates to a Reynolds number of $7.3 \times 10^{4}$ based on the shock strut (piston) diameter. At these conditions, the free stream turbulence level is less than $0.10 \%$. Additional information about the BART and recent studies therein related to airframe noise applications can be found in Refs. 21-25. 


\section{B. Nose Gear Model}

The model used in the present study is a quarter scale high-fidelity replica of a Gulfstream G550 nose landing gear that includes part of the lower fuselage section and the gear cavity. To duplicate the angle-of-attack effect during flight, inherent in the model design is an inclination angle of 3 degrees relative to the flow direction. The nose gear/fuselage arrangement is shown in Fig. 1a, where the flow direction is from right to left (i.e., along the $\mathrm{X}$ axis). The model was fabricated to faithfully represent the actual nose landing gear of the G550 aircraft while maintaining a geometry resolution of 0.3-0.4 inches $(8-10 \mathrm{~mm})$ on the full-scale level. This included the light cluster, steering mechanism, and the primary hydraulic and electrical lines, all of which were designed to be individually removed to determine their aeroacoustic significance. The reduced scale model mandated certain modifications to the original gear geometry in order to enable adequate structural integrity and to accommodate the planned instrumentation of the model. However, minimizing any side effects on the aeroacoustic characteristics of the model was an important consideration in introducing those modifications. The various components and subcomponents of the G550 nose landing gear are identified in the gear schematic presented in Fig. 1b. The designations of "port" and "starboard" are maintained consistent with the actual aircraft geometry. However, since the model was tested upside down, the position designations "upper" and "lower" are used for the model as tested in the wind tunnel.

The nose gear model was heavily instrumented. The wheels, door, fuselage, and cavity were instrumented with longitudinal and lateral distributions of static pressure orifices for measuring steady surface pressures. A schematic of the wheel geometry is shown in Fig. 2. Static pressure orifices on the port wheel were distributed along two radial arms that wrapped around from inside the hub on the outboard part of the wheel to inside the hub on the inboard part of the wheel. The starboard wheel had a circumferential distribution of static pressure orifices spaced every $20^{\circ}$. To enable pressure measurements at additional locations, the port and starboard wheels were provided with pins on the axes to allow "clocking" of their azimuthal angles to $\pm 20^{\circ}$, in $10^{\circ}$ increments. To measure unsteady surface pressures, 16 miniature, flush-mounted, piezoresistive, differential pressure transducers were mounted on various gear components. One of those transducers was installed in a "mobile" fashion, allowing it to be placed at numerous other locations on the model. The numbering and location of each of the 16 unsteady transducers is given in Table 1. The locations of 14 of the 16 transducers are shown in Figs. 3a-3d. The sensors are shown in Fig. 3b with protective tape over them, which was removed before testing. The sensors not shown are \#14, on the wheel axle, and \#16, which was the "mobile" transducer (shown in a later figure, adjacent to sensor 15). The miniature size of these "flat-pack" transducers enabled easier mounting, even on relatively small gear parts, while providing an adequate combination of sensitivity and frequency bandwidth (up to at least $16 \mathrm{kHz}$ ).

To help produce a turbulent boundary layer prior to flow separation from the shock strut, serrated transition strips were attached along the length of the shock strut in the regions between $\theta=50^{\circ}$ and $\theta=60^{\circ}$ and between $\theta=300^{\circ}$ and $\theta=310^{\circ}$, azimuthally. The choice of tripping configuration was based on earlier experiments. ${ }^{24,25}$ Similar tripping of the boundary layers on the wheels failed to produce any noticeable changes in the measured surface pressures; those strips were subsequently removed. The other primary gear components, mostly fabricated from polycarbonate material, can also be assumed to have experienced either transitional or turbulent flow due to the inherent surface roughness (which is expected to vary from approximately 64 to 256 micro inches in terms of rms height).

The model was tested in the full configuration, called "fully dressed", with all components present, and subsequently in various stages involving successive removal of selected parts, resulting lastly in the simple configuration, called "partially dressed", with the steering mechanism, hydraulic lines, and lights removed. The cavity from which the landing gear emerged was run in both open and closed configurations. The two heavily tested, primary configurations of interest were the fully dressed configuration with cavity open and the partially dressed model configuration with cavity closed. It is a goal of the NASA-Gulfstream partnership to establish this latter configuration, and the associated aeroacoustic database, as a benchmark problem for nose gear aeroacoustics.

\section{Measurement Techniques and Error Analysis}

Steady and unsteady pressures were simultaneously measured over the model using the static orifices and unsteady transducers described in the previous section. An electronic scanning pressure system was used to acquire the steady pressures, which were then converted to pressure coefficients. For the unsteady pressures, signals from 
the piezoresistive transducers were amplified and then sent to the A/D converter where they were AC-coupled, lowpass filtered at $20 \mathrm{kHz}$, and digitized using a sample rate of $51.2 \mathrm{kHz}$ and sample duration of 32 seconds. To check the calibration coefficients and monitor the health of the transducers during the test, the signals for the transducers in the circumferential arrays were split before the A/D converter so the total signal could be digitized at a slower rate, averaged, and compared to the static pressure data. In general, this check showed that the transducers were quite stable and experienced little drift during the course of the test. Estimates of uncertainty for the steady and unsteady pressure measurements and for the Particle Image Velocimetry (PIV) measurements are given in Table 2.

The PIV measurement techniques used in this study were a combination of the approaches used in the previous ${ }^{24,25}$ BART entries. Two-dimensional (2-D) PIV provided detailed insight into the steady and unsteady nearfield flow structure. The system features two high-resolution video cameras with a sensor size of 1360 pixels by 1024 pixels. The cameras were mounted to a traverse system surrounding the tunnel along with the laser and lightsheet optics. A $2 \mathrm{~mm}$ thick light sheet was generated using a pulsed, frequency-doubled, $200 \mathrm{~mJ} \mathrm{Nd}-\mathrm{YAG}$ laser operated at $5 \mathrm{~Hz}$. The light sheet was aligned for both, horizontal and vertical planes. Images were acquired using a $50 \mathrm{~mm}$ lens to obtain a field-of-view for a single camera that was approximately $152 \mathrm{~mm}$ long by $116 \mathrm{~mm}$ wide. Two cameras were used and the fields of view were overlapped to achieve an effective field of view of approximately $152 \mathrm{~mm}$ long by $227 \mathrm{~mm}$ high. The entire room housing the tunnel was seeded with nominally 1 micron particles produced by a theatrical fog machine. A minimum of 1000 image pairs were acquired for each configuration and processed with a 24 pixel by 24 pixel interrogation window. Statistical convergence was confirmed by examining the asymptotic behavior of the first and second moments of the velocity at select points in the flow field where the velocity gradient and turbulence intensities achieved their highest values. The spatial resolution for the field of view was approximately $1.3 \mathrm{~mm}$ for a 24-pixel interrogation window. Specifications for the PIV system are shown in Table 3.

\section{Discussion of Results}

Aside from the fully- and partially-dressed configurations, the staged removal of hydraulic and electrical lines, light cluster, and steering mechanism resulted in several intermediate configurations whereby steady and unsteady surface pressure measurements (no PIV) were collected. Placement of the "mobile" transducer at numerous locations on the gear model generated a vast array of additional unsteady data. Post processing of the data acquired from these intermediate configurations, plus the majority of the recordings from the mobile transducer, is ongoing and will be reported elsewhere. The present paper is devoted to the discussion of a small subset of results limited to the fully- and partially-dressed primary configurations. In the remainder of this paper, for ease of presentation and comparison of the results for the two primary configurations, the acronyms FDCO and PDCC will be used repeatedly to represent the fully-dressed gear with cavity open configuration and the partially-dressed gear with cavity closed configuration, respectively. Although measurements were made at multiple Mach numbers, the primary speed of interest was $\mathrm{M}=0.166$. Therefore, unless specified otherwise, the discussions pertain to the results obtained at this reference speed.

\section{A. Static Pressure Distribution}

Distributions of static pressure coefficient, $C_{P}$, on key components for both FDCO and PDCC configurations are shown in Figs. 4-6. The displayed results correspond to the starboard and port wheels and the interior surface of the door. Over all, removal of components from the lower part of the gear does not greatly modify the pressure field that is experienced by the wheels (Figs. 4 and 5). The effect of wheel clocking is shown for the starboard wheel in Fig. 4. Given the $20^{\circ}$ spacing between the pressure ports along the circumference of the wheel, clocking in either positive or negative directions by $10^{\circ}$ produces a more refined distribution. However, further clocking at other angles provides no additional information and is used here only to demonstrate the repeatability of the measured data. Except for a slight asymmetry, the circumferential pressure distribution appears to be similar in shape to the distribution around a circular cylinder with a large aspect ratio.

The radial distribution of $C_{P}$ at the $237^{\circ}$ location is shown in Fig. 5. Also plotted in Fig. 5 is the radial pressure profile at other angles obtained from clocking the port wheel through both positive and negative angles. The orifice location along the abscissa of the plot, $\mathrm{s}$, is expressed as percentage of the distance from the outside diameter of the 
wheel outboard hub to the outside diameter of the inboard hub. As seen in Fig. 5, the values of $C_{P}$ vary in a regular pattern out to an s value of about $80 \%$, being more negative at the positive clocking angles and less negative at the negative clocking angles. Beyond $\mathrm{s}=80 \%$, the pressure orifices are closer to the wheel axis and, therefore, likely to be influenced by the proximity to the hub or its separated wake. Comparing the profiles in Fig. 5a and 5b show no significant differences between the FDCO and PDCC pressure values. The pressure data for $20^{\circ}$ clocking in Fig. $5 \mathrm{~b}$ were corrupted and so, were not included. For both configurations, the azimuthal surface pressure variation near the wheel rim and the inboard hub is relatively weaker than that in the middle, at least over the range of $217^{\circ}$ to $257^{\circ}$.

The lateral distribution (starboard to port) of static $C_{P}$ for the door interior surface is shown in Fig. 6. The rows vary from upper to lower, numbers 1 through 9. For the FDCO configuration (Fig. 6a), as the orifices in the upper rows (rows 2, 3, and 4) approach the port side of the door, the $C_{P}$ values get increasingly positive. These higher rows show a significant lateral asymmetry in the distribution of pressure on the upper part of the door. This asymmetry is due to the presence of the gear steering mechanism on the starboard side. The wider wake from the gear steering mechanism hits the starboard side of the upper part of the door and results in less pressure recovery compared to the flow field on the port side. In comparison, the narrower wake emanating from the stripped down main strut in the PDCC configuration partially recovers before arriving at the interior surface of the door, resulting in a better and more symmetric pressure recovery.

\section{B. Fluctuating Pressures at Selected Surface Locations}

A good understanding of surface pressure fluctuations is the first critical step in most airframe noise problems. Given that the nose gear is a collection of bluff bodies of different shapes and sizes, and that the flow has a relatively low Reynolds number, one might expect the surface pressure to have a prominent tonal character superposed on a broadband background fluctuation field. For this reason, the 16 pressure transducers were strategically placed on gear components at locations where either a self-sustained unsteady flow or a highly interactive flow field resulting from wake impingements from upstream components was expected. Typically, impinging wakes on downstream components generate high amplitude pressure fluctuations, which are the critical ingredient of many airframe noise sources.

In Fig. 7, the FDCO fluctuating pressure coefficient, $C_{P^{\prime} r m s}$, is shown for the 16 unsteady pressure transducers. Transducers 2, 6, and 12 stopped functioning during the initial set of measurements in BART; therefore no data are displayed for these locations. Transducer 1 was located on the cavity floor and transducer 16 (mobile sensor) was placed on the back wall. They measure the lowest pressure levels among the active sensors, indicating a relatively quiescent cavity flow. The change in $C_{P^{\prime} r m s}$ with Mach number is generally insignificant for most sensors and

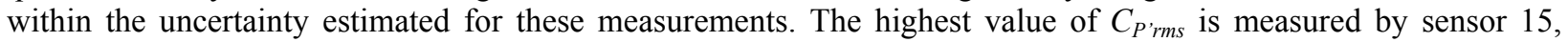
which was located on the larger of the two "torque arms" downstream of the piston (Fig. 3a). Figure 8 shows a close up view of sensor 15. The sensor was fixed and embedded into the upstream rib of the torque arm on the right side. The vertical position of this sensor was chosen so that the local width of the torque arm closely matched the width of the wake originating from the piston. Thus, the sensor was near the impingement location of the free shear layer expected to emanate from the cylindrical piston. (Note when the photograph was taken, the mobile sensor was placed at the same vertical height as sensor 15 but on the opposite edge of the torque arm and will be referred to later in the text). In front of the torque arm is the upstream piston with its serrated transition strip, seen prominently in the picture.

Power spectral densities (PSD) from the fixed transducer on the torque arm at the three test Mach numbers are shown in Fig. 9a. The overall spectral levels scale with the free-stream dynamic pressure as expected, consistent with the corresponding variation of the RMS pressure shown on the plot. Figure 9b shows the normalized PSD curves associated with the three Mach numbers using a dynamic pressure scaling of the amplitude. A good collapse of the data is obtained. However, it must be pointed out that not all sensor locations produce such a tight collapse of the normalized PSD data. In particular, sensors 3, 4, and 10 located on the door display observable deviation for the $\mathrm{M}=0.12$ results when normalized in a similar fashion. Such a behavior suggests that Reynolds number effects may not be negligible at the lowest velocity tested. But more importantly, such effects could be component dependent. Surprisingly, these spectra do not reveal any narrow band peaks that might have been associated with a quasiperiodic wake shedding from the strut. The spectral cutoff at $20 \mathrm{kHz}$ indicates the upper bound on the analysis frequency bandwidth. 
To further investigate the absence of Strouhal type shedding behind the cylindrical strut, the mobile sensor was placed at various positions on the model, including $160^{\circ}$ and $180^{\circ}$ on the downstream side of the shock strut cylinder. These positions on the backside of the strut were selected in order to prevent the fairing that housed the mobile transducer from altering the natural wake development. Scrutiny of the measurements from the backside of the strut showed no significant local peaks in the unsteady pressure spectrum. Moving the mobile sensor vertically along the strut axis also failed to reveal any evidence of a prominent tonal behavior. As a further diagnostic step, the mobile sensor was then placed opposite to the fixed sensor on the torque arm as shown in Fig. 8. A comparison of the spectra from the fixed and mobile sensors at their respective locations on the torque arm is shown in Fig. 10. The two spectra are nearly identical, suggesting that the strut wake approaching the torque arm is symmetric and devoid of any large scale vortical structures. It appears that proximity of the torque arm to the shock strut suppresses periodic shedding. In previous studies ${ }^{25}$ on tandem cylinders, this effect was evidenced when the downstream body was in close proximity to the upstream body, yielding a strictly broad-band spectrum with no tonal components.

The comparison of $C_{P^{\prime} r m s}$ values between the FDCO and PDCC configurations is provided in Fig. 11. Removal of components from the lower part of the landing gear has the most significant effect on the unsteady pressures on the door (sensors 3, 4, and 10) and the drag brace (sensors 5 and 8). These sensors are located directly behind the main strut from which the hydraulic lines, lights, and steering mechanism were removed to create the partially dressed configuration. At each of these sensor locations, the energy level of the fluctuations increases substantially from the FDCO to PDCC configuration. It is likely that the presence of the additional components in FDCO creates a barrier to the oncoming flow, resulting in a wider, less energetic wake impinging on the downstream drag brace and door and, hence, in lower levels of $C_{P}{ }^{\prime}$ rms for the fully dressed configuration. Returning to Fig. 11, the surface pressure fluctuations mainly associated with the upper part of the nose gear, comprised of the wheels (sensors 7 and 13) and upper and lower torque arms (sensors 14 and 15), remain unaffected by the configuration changes, analogous to the static pressure distributions in that region (Figs. 4 and 5).

Sample spectra at select locations are shown in Fig. 12 for both FDCO and PDCC configurations. The upper region of the door on the starboard side (sensor 3) shows a significant increase in spectral levels across most of the measured frequency band (Fig. 12a). This is consistent with the large increase in $C_{P^{\prime} r m s}$ shown in Fig. 11, and is likely due to the fact that the removed steering mechanism was primarily on the starboard side of the gear main strut (Fig. 3b). Not shown, the spectra for the upper region on the port side of the door (sensor 4) exhibited less of a difference due to component removal than the starboad side and the difference was mostly below $1 \mathrm{kHz}$. To capture the effect of the impinging wake from the steering mechanism on the surface pressure field in the mid-section of the door, sensor 10 was located slightly starboard of the door vertical centerline. The spectra at this location, plotted in Fig. 12b, indicate a departure between the FDCO and PDCC spectra mostly below $500 \mathrm{~Hz}$. Again, the increase in the fluctuation levels for the partially dressed case is attributed to the absence of the steering mechanism.

The other two locations showing significant changes between the FDCO and PDCC configurations were on the drag brace, which was in closer proximity to the removable components than the door. The spectra for the fluctuations on the upper part of the drag brace (sensor 5) are displayed in Fig. 12c. Their shape and relative differences are similar in character to those obtained on the upper part of the door (Fig. 12a). This is not unexpected since this sensor is on the starboard side of the drag brace and in somewhat close proximity to the steering mechanism. The spectra from the lower part of the drag brace (sensor 8 on the port side of this component) depicted in Fig. 12d, indicate an opposite trend to the other spectra shown thus far. That is, the PDCC spectra show increased levels at intermediate and high frequencies (above $200 \mathrm{~Hz}$ ). Discordant effects of component removal over different portions of the frequency spectra cannot be explained on the basis of the measured data alone and it is hoped that numerical simulations will shed more light on these observations.

The PSD plots from inside the wheel hub cavity (sensor 7) are shown in Fig. 12e. The spectra for the two configurations are nearly identical highlighting the fact that the flow field on the upper part of the gear remains unaffected from removal of gear components.

Fairing of landing gear components is a well known strategy used to reduce landing gear noise. It attempts to shield the smaller scale components from the incoming flow as well as to streamline the resulting wake flow. The results presented in Figs. 11 and 12 suggest that streamlining the flow may indeed have unintended consequences. While a faired component may produce lower levels of flow unsteadiness, the resultant accelerating flow may generate much higher levels of fluctuations on the downstream components and thus, producing no net gain in noise reduction or even worse increasing the radiated sound levels from the faired body. The lesson learned is that a more 
holistic view of the gear flow field must be kept in mind when modifications of the gear geometry are being contemplated.

\section{2D PIV Measurements}

PIV measurements can be extremely effective at clarifying the nature of the flow features both in between and behind the landing gear components, as well as providing the quantitative information necessary to validate numerical simulations of the complex flow fields. Resolving the highly three dimensional (3D) velocity field associated with the nose landing gear would require the use of the stereo PIV techniques. However, the geometric complexity of the landing gear configuration, including the close proximity of the gear components and lack of optical access between a pair of adjacent components, made the stereo PIV approach extremely time consuming and impractical. Ultimately, we decided to aquire 2D planar PIV measurements where high-quality, high-confidence data could be obtained and processed. Typically, at each planar location, at least 1000 image pairs were recorded in order to ensure convergence of the extracted statistical information. Both higher resolution $(0.77 \mathrm{~mm})$ but smaller field-of-view data and lower resolution $(1.3 \mathrm{~mm}$ ) but larger field-of-view data were acquired during 2007 and 2008 tunnel entries, respectively, in order to meet the disparate needs of quantifying small-scale unsteady structures and obtaining a more global view of the larger scale flow field. Processing of the latter set of PIV data is ongoing at this time; however, sample results for select planes are presented below.

Two-dimensional PIV measurements were made in four horizontal planes (Fig. 13), each planar measurement consisting of two overlapping rectangular regions. The plane closest to the fuselage, plane 1, was located vertically $2 "(50.8 \mathrm{~mm})$ below the door upper ventilation slot. The origin of the local coordinate system within this plane was along the vertical edge (port side) of the door at the point where the door starts to taper (see schematic in Fig. 6). Plane 2 was located vertically 4.44" $(113 \mathrm{~mm})$ below the wheel hub center. The origin for this plane was at the door centerline, at the top aft edge. Planes 3 and 4 were located at the level of the wheel hub center, plane 3 being in the wake of the wheels, and plane 4 located outboard of the starboard wheel. The origin for plane 3 was at the downstream corner of the port wheel chine (the extended lip on the side of the tire that prevents foreign object damage to the wheel hub). The origin for plane 4 was at the upstream corner of the starboard wheel chine. In each PIV image shown in this paper, the location of the relevant origin corresponds to the $(0,0)$ coordinate point displayed in the contour plots. Since two adjacent co-planar regions were measured simultaneously via two cameras, the two data regions had to be merged based on their location when the optical system was calibrated. Because the side-by-side cameras view the overlapping areas from different perspectives and no two cameras and lenses are identical, the data contours from respective measurement regions are not expected to match perfectly. Such a potential mismatch should be borne in mind while viewing the distribution of turbulent kinetic energy (TKE), mean vorticity, and mean streamwise velocity in the following figures. All PIV measurements were made at $\mathrm{M}=0.166$.

For aeroacoustic modeling purposes, an in-depth knowledge of the fluctuating flow field is of paramount importance. The knowledge of turbulent kinetic energy (TKE) distribution can provide critical insights into the location and nature of the hot spots where flow unsteadiness is elevated. Contours of TKE derived from the larger field-of-view PIV measurements in plane 1 are presented in Figs. 14a and 14b for the case of FDCO and PDCC configurations, respectively. The reader is reminded that the TKE plots contain only the in-plane components of the velocity fluctuations. For all PIV contour plots, dimensions in $\mathrm{X}$ and $\mathrm{Y}$ are in millimeters and the flow is always from left to right, as shown by the arrows in these two plots only. Clearly at this plane, the fluctuation level in the wake of the door is much lower for the fully dressed configuration. The wake is also wider due to the presence of the dressing as will be in evidence at other stations. The partially dressed gear produces much stronger shear layers at the door edges, particularly on the starboard side. Notice the wake remains asymmetric, despite the fact that the PDCC configuration is symmetric with the exception of a couple of small protuberances on the main strut that are used to hold the steering mechanism in place. Yet, these small subcomponents have first order effects on the global flow field. As a comparison with the larger field-of-view data in Fig. 14b, the corresponding higher resolution $(0.77$ $\mathrm{mm}$ ) data from the 2007 BART entry, is shown in Fig. 14c. The rectangular region for this earlier, higher resolution data was determined on the basis of our initial assumption of a sharp separation at the edge of the door leading to a significant shear layer rollup activity behind the door. As shown in Figs. 14b and 14c, however, no roll-up activity existed and the higher resolution data even missed most of the (relatively thicker) shear layer. In light of this finding, the remainder of the PIV data shown below will be based on the lower-resolution $(1.3 \mathrm{~mm})$ but more global view of the flow field. 
The corresponding out-of-plane vorticity component for the FDCO and PDCC configurations is shown in Figs. $14 \mathrm{~d}$ and $14 \mathrm{e}$, respectively. In this case, the main distinction between the two is a higher vorticity level in the shear layer for the partially dressed configuration on the starboard side of the door (lower portion of the plot in Fig. 14e). To further investigate the possibility of shear layer rollup behind the door, we examined the instantaneous vorticity distribution based on individual snapshots from the 1000-frame ensemble of PIV images. The majority of the frames revealed no evidence of rollup. Fig. 14f shows a rare example of the beginning of a large-scale rollup of the starboard side shear layer. It appears that most of the flow field behind the door was dominated by a random field of positive and negative vorticity, where the door edge shear layers trail off and are rapidly broken up into smaller scale vorticity lumps (e.g., the upper portion of the plot in Fig. 14f). It is not clear to us if the shear layer break up is due to Kelvin-Helmholtz instability or to some other flow dynamic. The mobile unsteady pressure transducer was placed at numerous locations on the back side of the door, including at the edges slightly above and below the location of this laser sheet station. Spectra for the transducer at two edge locations, upper and lower, near the laser sheet on the starboard door edge are shown in Fig. 15. Clearly, there are no sharp tonal peaks, only a slight "hump" for the lower spectrum, indicating that no clearly-defined rollup existed in the wake of the door. Spectra for the port side did not show a hump.

Contours of mean streamwise velocity downstream of the piston-torque arm tandem configuration (plane 2) for the fully dressed and partially dressed gear are shown in Figs. 16a and 16b, respectively. Small circular spots and imperfections in the contours are due to reflections from door surface features (screws, slots, etc.) visible beneath the laser sheet, even though everything was painted flat black. There is a distinct difference in wake width between the two gear configurations where the fully dressed configuration pushes the wake out much wider than the partially dressed configuration, presumably due to the presence of the light cluster and the steering mechanism. The near symmetric wake produced by the partially dressed gear suggests a diminishing effect of the minor protuberances of the main strut at this PIV plane. Corresponding distributions of the two-dimensional TKE are shown in Fig. 16c and $16 \mathrm{~d}$, respectively, where the level of velocity fluctuations appears to be much higher directly behind the torque-arm for the fully dressed gear. In Fig. 16d, for the partially dressed configuration, the increased levels of TKE further downstream $(x>50 \mathrm{~mm}$. and $\mathrm{y}=+/-20 \mathrm{~mm}$.) within the wake region may suggest that the wake is not a twodimensional entity, but that the energetic regions are moving vertically up or down into the measurement plane due to the complex 3D geometry in the region (door, fuselage, wheels, etc.).

Figure 17 shows the mean streamwise velocity, TKE, and spanwise vorticity in the wake of the wheels, at the center of the wheel hub (plane 3), for the FDCO configuration. At this level, there was no significant difference in the flow fields for the two gear configurations, since this plane was far enough removed from the areas of the gear where the changes were made. High levels of TKE are evident in Fig. 17b, apparently due to the juncture of the wheel axle and the upper torque-arm that is located between the wheels, which may indicate a large source of noise. Vorticity from the lips (chines, Fig. 1b) on the external sides of the wheels are seen in Fig. 17c. Fig. 17d shows the wheel axle-upper torque arm junction.

PIV Plane 4 was also at the level of the center of the wheel hub, but on the external side of the starboard wheel, across the horizontal symmetry plane. Mean streamwise velocity in this plane is shown in Fig. 18a. The flow coming around the sharp edge of the forward lip (chine) results in stagnated flow downstream in the wheel hub area. Fig. $18 \mathrm{~b}$ shows spanwise vorticity and reveals an area of highly rotational flow in the separated shear layer from the chine. The corresponding TKE is plotted in Fig. 18c. Clearly, the free shear layer separating off the chine at the front of the wheel convects downstream and back into the rear part of the wheel hub area. This impingement area was shown to be the second most active area in the $C_{P^{\prime} r m s}$ distribution (sensor 7 in Fig. 7). The high values of $C_{P}{ }^{\prime}{ }^{\prime} r s$ were likely due to the flow pattern shown here in Fig. 18c. In this and the previous figure, vertical black lines are shown cutting across the shear layer. These are locations where profiles of TKE and vorticity will be shown later.

TKE distribution for the PDCC gear was found to be nearly identical to that depicted in figure 18c; thus, it will not be shown here. The similarity corroborates the earlier observation that this plane was far enough removed from the areas of the gear where the changes were made to show any significant differences. As mentioned earlier regarding the previous wind tunnel entry, higher resolution images were obtained and are shown for vorticity and TKE in Fig. 18d, and 18e, respectively. Comparing Fig.18d and 18b for vorticity and Fig. 18e and 18c for TKE, it is clear that the higher resolution measurements reveal a more refined picture of the shear layer near the tire chine in conjunction with higher levels of these two flow quantities. This is shown more distinctly in profiles of TKE and vorticity in Figs. 19a-19d. The higher peak levels are shown for the higher resolution measurements ("2007"), versus the current measurements ("2008"). A similar disparity in TKE levels had been noted in the context of our 
previous measurements of the shear layer flow behind the cusp of the leading edge slat of a high-lift configuration (Fig. 12a from ref. [26].) However, the thickness of the shear layers is only slightly affected, being about the same in the TKE profiles, and slightly wider for the current measurements in the vorticity profiles. Overall, both highresolution and medium-resolution PIV measurements produce consistent results. As stated earlier, the desire to obtain a global view of the flow field became the more important priority during the 2008 entry.

A selected snapshot of instantaneous vorticity based on plane 4 measurements is shown in Fig. 20. The shear layer trailing from the chine can be seen with discrete roll-up along its length. It moves aft nearly to the rear lip. Areas of opposite-sign vorticity can be seen in the hub area. Occasionally, the instantaneous frames would show an apparent ejection of this vorticity from within the hub across the trailing shear layer.

\section{Summary}

Detailed high-quality aeroacoustic measurements for landing gears are crucial to obtaining a clear understanding of critical unsteady flow features in the vicinity of the gear components and the associated noise generation mechanisms. Such understanding would open the door to suitable flow alterations that would lead to reduced intensity of farfield noise. Moreover, these in depth measurements are also necessary for benchmarking highfidelity CAA simulations of landing gears. Currently, such a comprehensive experimental database does not exist and the measurements described herein represent the first part of a larger campaign to acquire a database of this type for a nose landing gear. Specifically, selected aspects of the near-field flow have been mapped using a combination of steady and unsteady pressure measurements along with particle image velocimetry. The most extensive datasets have been obtained for the fully-dressed gear configuration with cavity open and the partially-dressed gear with cavity closed.

Using the unsteady pressure data obtained via sixteen strategically placed sensors along various components of the nose gear, we have identified the locations of (relatively) high intensity pressure fluctuations over the gear surface. Removal of select landing gear components is shown to result in stronger pressure fluctuations at certain surface locations. With or without those removable components, the measured frequency spectra are shown to be primarily broadband in character, i.e., generally devoid of any local peaks associated with sustained Strouhal shedding. It is plausible that the close proximity of the gear components is responsible for inhibiting the process of vortex shedding.

PIV measurements in four horizontal planes also failed to reveal any large-scale vortical structures being shed from different gear components, thus corroborating the unsteady pressure data. Associated distributions of turbulent kinetic energy (TKE) and out-of-plane vorticity component indicate the nose gear flow field to be comprised of mainly separated shear layers of differing strength and orientation. Snapshots of the instantaneous vorticity showed very limited evidence of any large-scale vortex roll-up at the edges of the landing gear door, consistent with the absence of any distinct tonal peaks in the surface pressure spectra over the door surface. The door wake for the fully dressed configuration was wider in comparison with that for the partially dressed gear. High levels of TKE and $C_{P^{\prime} r m s}$ were measured near the hub area on the wheels, suggesting that this area may be one of the stronger sources of noise.

\section{Acknowledgments}

The authors express their appreciation to Mr. Donald Day and Mr. David Palmer for their assistance with the experimental setup, instrumentation, and data acquisition; Mr. Jerome Harris for optical setup and assisting with data acquisition during the PIV measurements; Mr. Tom Hall and Mr. Mick Hartzheim for installation and wiring of the pressure transducers; and to Mr. Gary Wainwright and Mr. Ronnie L. Barnes for the model development and fabrication. We would also like to thank Carl Rogers and Scott Verden of AS\&M Inc. for their help with geometry definition and modifications and instrumentation placement. Finally, we would like to thank the Gulfstream Aerospace Corporation, and notably, Mr. Thomas Van de Ven, for their support.

\section{References}

\footnotetext{
${ }^{1}$ Michel, U. and Qiao, W., "Directivity of Landing-Gear Noise Based on Flyover Measurements," AIAA-99-1956, May,
} 1999. 
${ }^{2}$ Khorrami, M.R., Lockard, D.P., Humphreys, Jr., W.M., Choudhari, M.M., and Van de Ven, T., "Preliminary Analysis of Acoustic Measurements from the NASA-Gulfstream Airframe Noise Flight Test," AIAA Paper 2008-2814, May, 2008.

${ }^{3}$ Piet, J.-F., Michel, U., and Böhning, P., "Localization of the Acoustic Sources of the A340 with a Large Phased Microphone Array during Flight Tests", AIAA Paper 2002-2506, May, 2002.

${ }^{4}$ Stoker, R., Guo, Y., Streett, C., and Burnside, N., "Airframe Noise Source Locations of a 777 Aircraft in Flight and Comparisons with Past Model Tests," AIAA Paper 2003-3232, May, 2003.

${ }^{5}$ Dobrzynski, W., Chow, L.C., Guion, P., and Shiells, D., "A European Study on Landing Gear Airframe Noise Sources," AIAA Paper 2000-1971, June, 2000.

${ }^{6}$ Piet, J-F, Davy, R., Elias, G. and Siller, H. A., Chow, L.C., Seror, C., and Laporte, F., "Flight Test Investigation of Add-On Treatments to Reduce Aircraft Airframe Noise," AIAA Paper 2005-3007, May, 2005.

${ }^{7}$ Elkoby, R., Brusniak, L., Stoker, R., Khorrami, M.R., Abeysinghe, A., and Moe, J.W., "Airframe Noise Results from the QTD II Flight Test Program,” AIAA Paper 2007-3457, Rome, Italy, May, 2007.

${ }^{8}$ Jaeger, S.M., Burnside, N.J., Soderman, P.T., Horne, W.C., and James, K.D., "Microphone Array Assessment of an Isolated, 26\%-Scale, High Fidelity Landing Gear,” AIAA Paper 2002-2410, June, 2002.

${ }^{9}$ Horne, W.C., James, K.D., Arledge, T.K., Soderman, P.T., Burnside, N., and Jaeger, S.M., "Measurements of 26\%-scale 777 Airframe Noise in the NASA Ames 40- by 80 Foot Wind Tunnel," AIAA Paper 2005-2810, May, 2005.

${ }^{10}$ Smith, M.G., Fenech, B., Chow, L.C., Molin, N., Dobrzynski, W., and Seror, C., "Control of Noise Sources on Aircraft Landing Gear Bogies," AIAA Paper 2006-2626, May, 2006.

${ }^{11}$ Ravetta, A.P., Burdisso, R.A., Ng, W.F., Khorrami, M.R., Stoker, R.W., and Abeysinghe, A., "Screening of Potential Landing Gear Noise Control Devices at Virginia Tech for QTD II Flight Test”, AIAA paper 2007-3455, Rome, Italy, May 2007.

${ }^{12}$ Li, F., Khorrami, M.R., and Malik, M.R., "Unsteady Simulations of a Landing-Gear Flow Field," AIAA Paper 2002-2411, June 2002.

${ }^{13}$ Hedges, L.S., Travin, A.K., and Spalart, P.R., "Detached-Eddy Simulations over a simplified landing gear," Journal of Fluids Engineering, Vol. 124, No. 2, pp. 413-423, June 2002.

${ }^{14}$ Lockard, D.P., Khorrami, M.R., and Li, F., “Aeroacoustic Analysis of a Simplified Landing Gear," AIAA Paper 20033111, May 2003.

${ }^{15}$ Lockard, D.P., Khorrami, M.R., and Li, F., "High Resolution Calculation of a Simplified Landing Gear," AIAA Paper 2004-2887, May 2004.

${ }^{16}$ Khorrami, M.R. and Lockard, D.P., “A Landing Gear Noise Reduction Study Based on Computational Simulation," in Proceedings of INTER-NOISE 2006, Published by the Institute of Noise Control Engineering of the USA, INC., December 2006.

${ }^{17}$ Seror, C., Sagaut, P., and Belanger, A., "A Numerical Aeroacoustics Analysis of a Detailed Landing Gear," AIAA Paper 2004-2884, May 2004.

${ }^{18}$ Georges, L., Hillewaert, K., Capart, R., Thomas, J.-F., and Geuzaine, P., "RANS-LES Simulations Around a Complete Landing Gear Geometry," $7^{\text {th }}$ International Symposium on Engineering Turbulence Modelling and Measurements - ETMM7, Limassol, Cyprus, June, 2008.

${ }^{19}$ Li, Y., Satti, R., Lew, P.-T., Shock, R., and Noelting, S., "Computational Aeroacoustic Analysis of Flow Around a Complex Nose Landing Gear Configuration,” AIAA Paper 2008-2916, May 2008.

${ }^{20}$ Zawaodny, N.S., Liu, F., Yardibi, T., Cattafeta, L.N., Khorrami, M.R., Neuhart, D., and Van de Ven, T., "A Comparative Aeroacoustic Study of a 1/4-Scale Gulfstream G550 Aircraft Nose Landing Gear Model," AIAA Paper 2009-3153, May 2009.

${ }^{21}$ Sellers, W. L. and Kjelgaard, S. O., "The Basic Aerodynamic Research Tunnel - A Facility Dedicated to Code Validation," AIAA Paper 1988-1997, May 1988.

${ }^{22}$ Washburn, A. E., "The Effect of Freestream Turbulence on the Vortical Flow over a Delta Wing," Master of Science Thesis, George Washington University, 1990.

${ }^{23}$ Jenkins, L. N., "An Experimental Investigation of the Flow Over a Notchback Automobile Configuration," Master of Science Thesis, George Washington University, 1999.

${ }^{24}$ Jenkins, L. N., Khorrami, M. R., Choudhari, M. M., and McGinley, C. B., "Characterization Of Unsteady Flow Structures Around Tandem Cylinders For Component Interaction Studies In Airframe Noise,”, AIAA Paper 2005-2812, 2005.

${ }^{25}$ Jenkins, L. N., Neuhart, D. H., McGinley, C. B., Choudhari, M. M., and Khorrami, M. R., "Measurements Of Unsteady Wake Interference Between Tandem Cylinders”, AIAA Paper 2006-3202, 2006.

${ }^{26}$ Choudhari, M. M. and Khorrami, M. R., "Effect of Three-Dimensional Shear-Layer Structures on Slat Cove Unsteadiness," AIAA Journal, Vol. 45, No. 9, 2007, pp. 2174-2186. 
Table 1. Unsteady Pressure Sensor Assignments

\begin{tabular}{|l|l|}
\hline $\begin{array}{l}\text { Sensor } \\
\text { Number }\end{array}$ & Location \\
\hline 1 & Cavity floor \\
\hline 2 & Cavity back wall \\
\hline 3 & Door, upper starboard (nearer wheel) \\
\hline 4 & Door, upper port (nearer wheel) \\
\hline 5 & Drag brace, upper (nearer wheel) \\
\hline 6 & Light \\
\hline 7 & Starboard wheel hub \\
\hline 8 & Drag brace, lower (nearer cavity) \\
\hline 9 & Steering mechanism \\
\hline 10 & Door, lower (nearer cavity) \\
\hline 11 & Steering mechanism, back side \\
\hline 12 & Cylinder (behind lights) \\
\hline 13 & Starboard wheel, exterior \\
\hline 14 & Wheel axle \\
\hline 15 & Torque arm (nearer cavity) \\
\hline 16 & Mobile transducer \\
\hline
\end{tabular}

Table 2. Estimated Experimental Uncertainties

\begin{tabular}{|l|l|}
\hline Steady Cp & 0.02 \\
\hline PIV: Umean, Vmean & $1.4 \mathrm{~m} / \mathrm{s}$ \\
\hline PIV: Spanwise Vorticity & $1042 \mathrm{~s}^{-1}$ \\
\hline PIV: TKE & $4 \%$ \\
\hline Power Spectral Density (PSD) & $10-20 \%$ \\
\hline Cp' ${ }_{\text {rms }}$ & $5-11 \%$ \\
\hline
\end{tabular}

Table 3. 2-D PIV Specifications

\begin{tabular}{|l|l|}
\hline Lightsheet thickness & $2 \mathrm{~mm}$ \\
\hline Lasers & Dual 220 mJ, Nd-YAG \\
\hline Digital camera frame rate & $5 \mathrm{~Hz}$ \\
\hline Sensor size & $1360 \times 1036$ pixels \\
\hline $\begin{array}{l}\text { Measurement volume (50 mm lens, 24X24 } \\
\text { pixel interrogation window) }\end{array}$ & $1.3 \times 1.3 \mathrm{~mm}$ \\
\hline Interrogation window overlap & $50 \%$ \\
\hline Flow seeding technique & Commercial fog generator \\
\hline Image pairs per configuration & 1000 \\
\hline Total field of view (50 mm lens) & $152 \mathrm{~mm}$ long x 227 mm wide \\
\hline
\end{tabular}




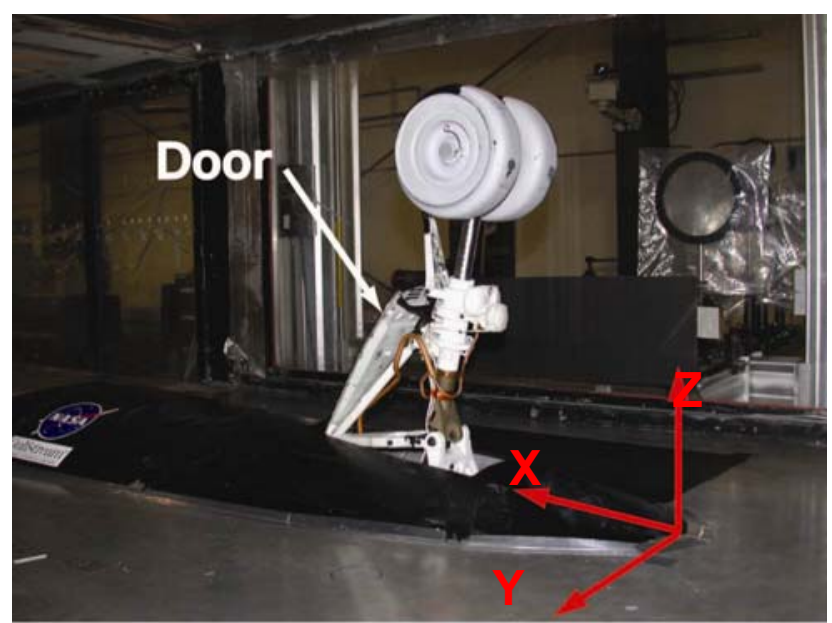

Figure 1a. Nose landing gear configuration in the BART facility.

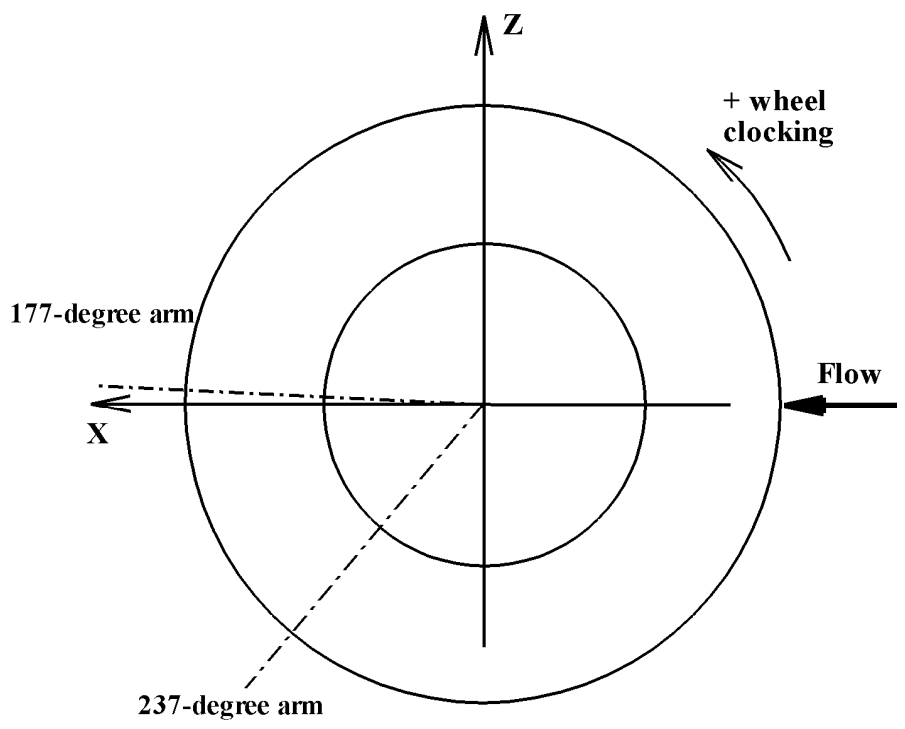

Figure 2. Wheel schematic showing coordinate axes and radial static pressure arms on the port wheel.

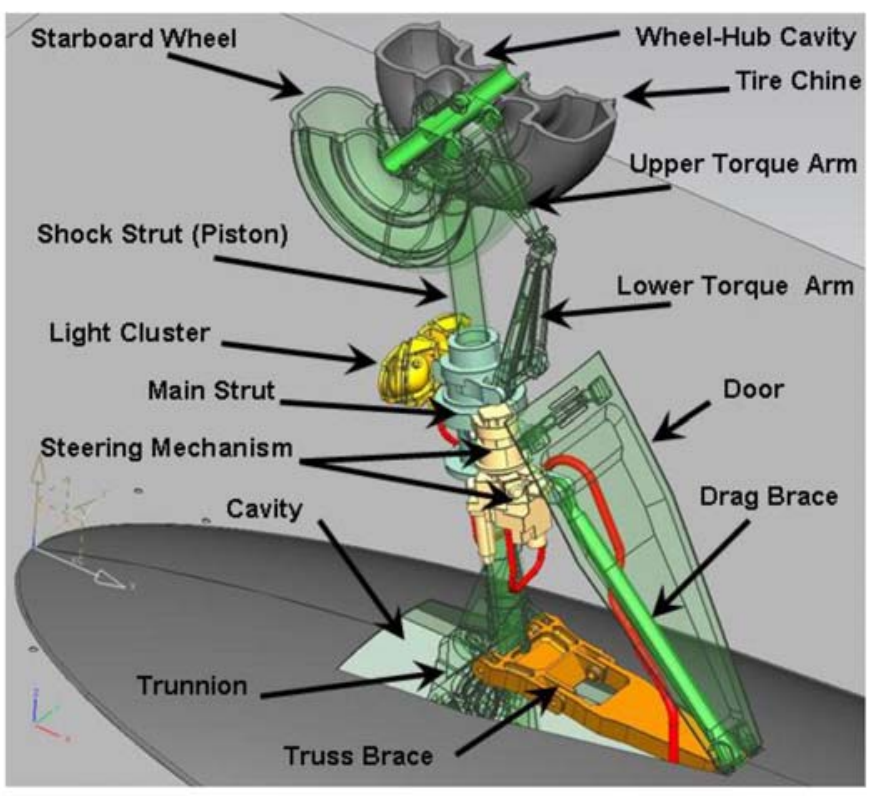

Figure 1b. Nose landing gear schematic identifying various components. 


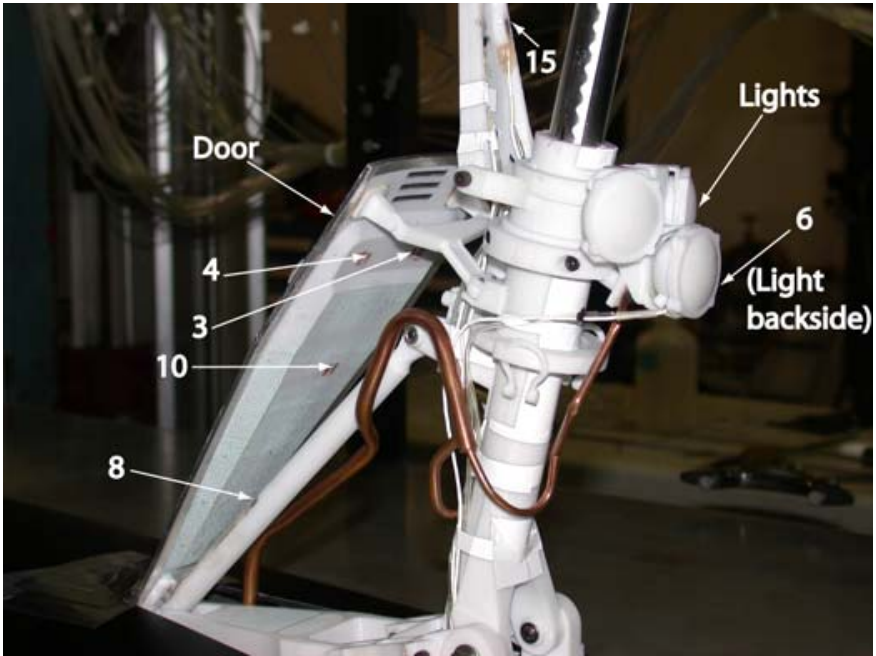

Figure 3a. Unsteady pressure sensors on model-port side.

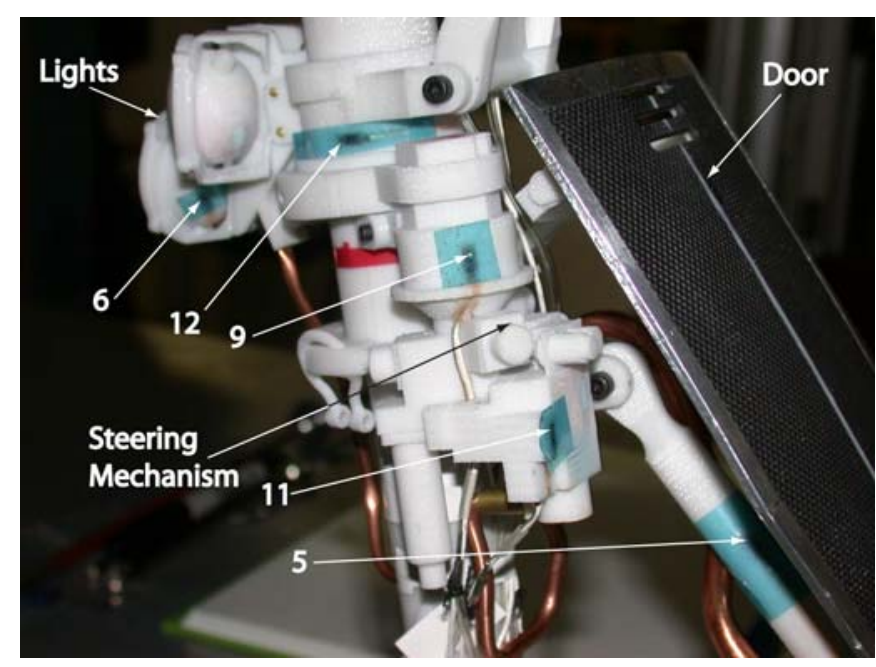

Figure 3b. Unsteady pressure sensors on modelstarboard side.

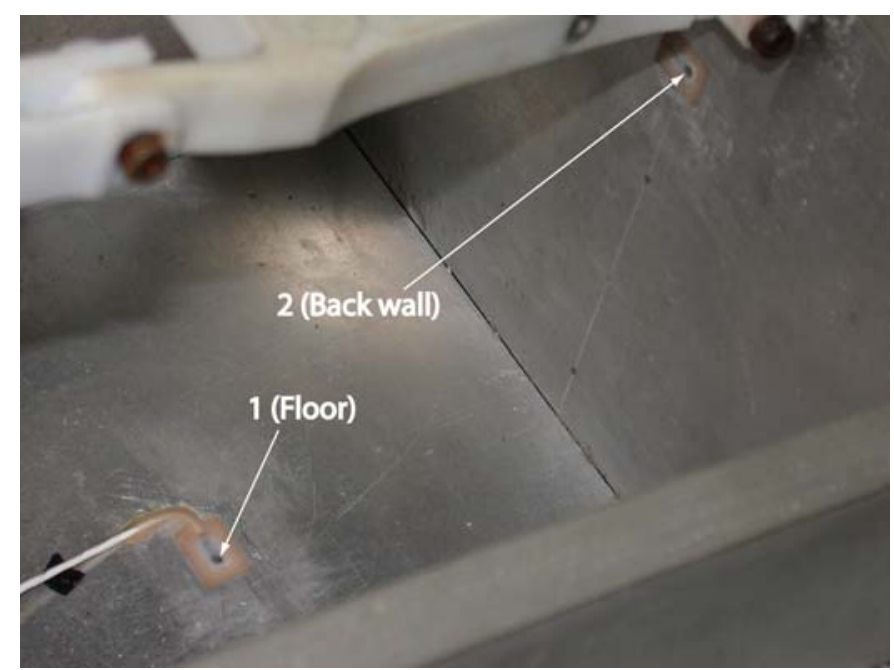

Figure 3c. Unsteady pressure sensors in cavity.

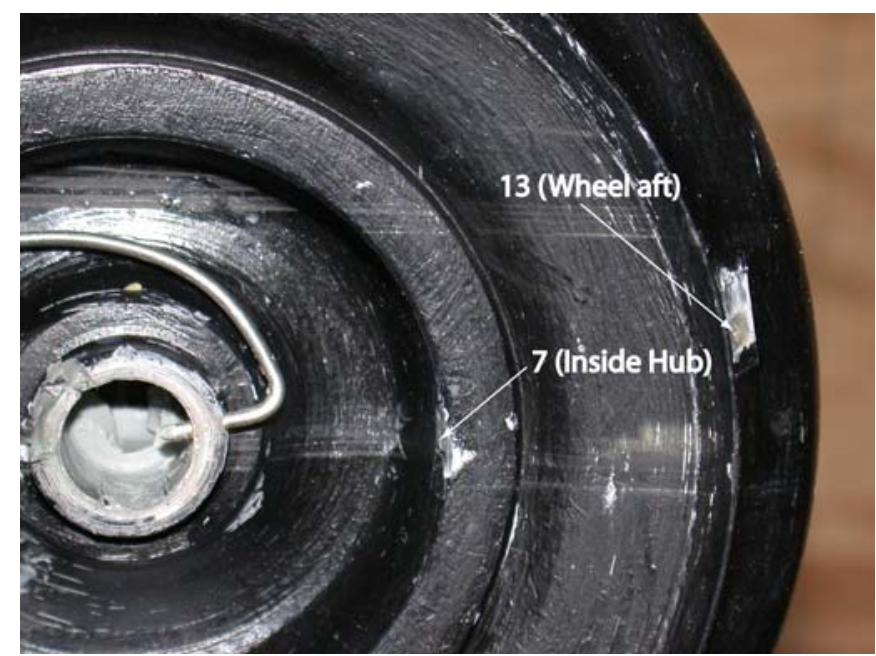

Figure 3d. Unsteady pressure sensors on starboard wheel. 


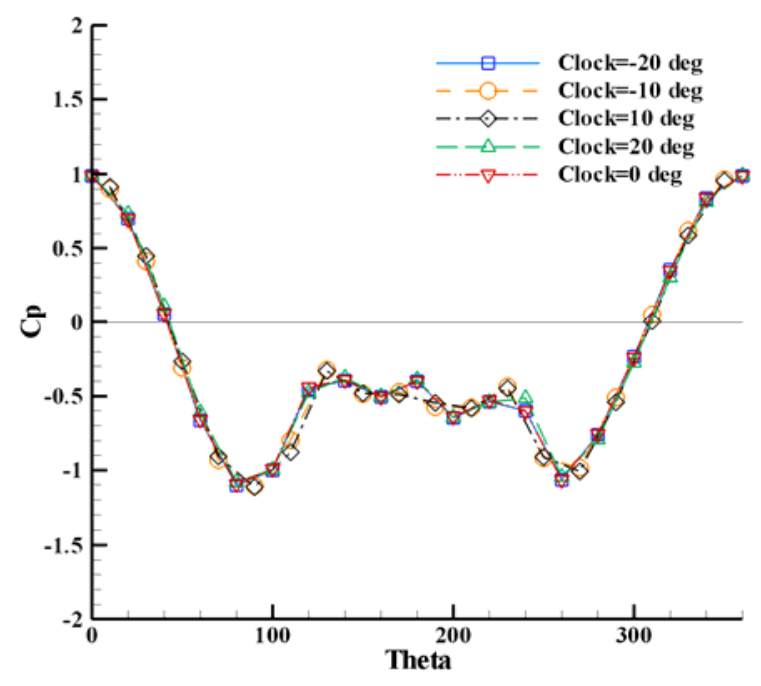

Figure 4a. Azimuthal variation of static $C p$ on starboard wheel - fully-dressed cavity open (FDCO) configuration, $\mathrm{M}=\mathbf{0 . 1 6 6}$.

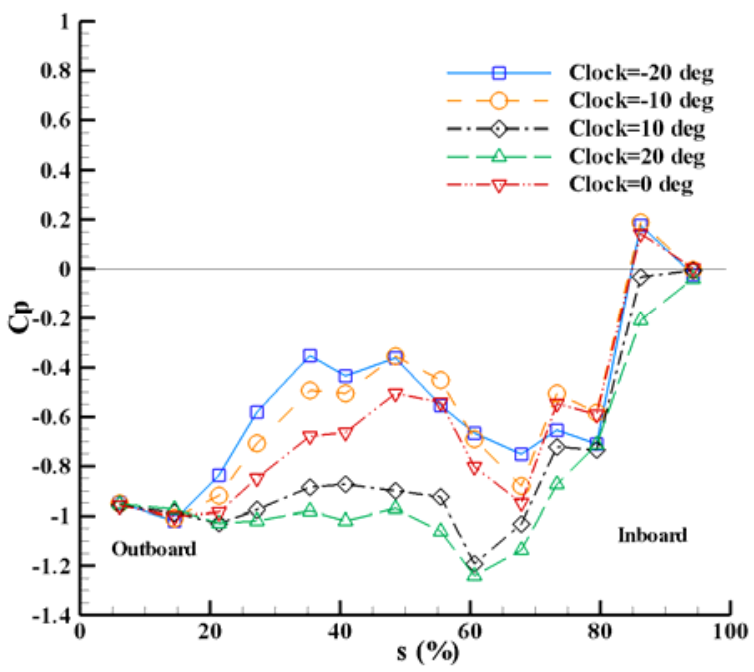

Figure 5a. Radial variation of static $\mathrm{Cp}$ along port wheel, $237^{\circ}$ arm- $F D C O$ configuration, $M=0.166$.

(Note: $+20^{\circ}$ clocking corresponds to $237^{\circ}$ arm moving to $257^{\circ}$, for example.)

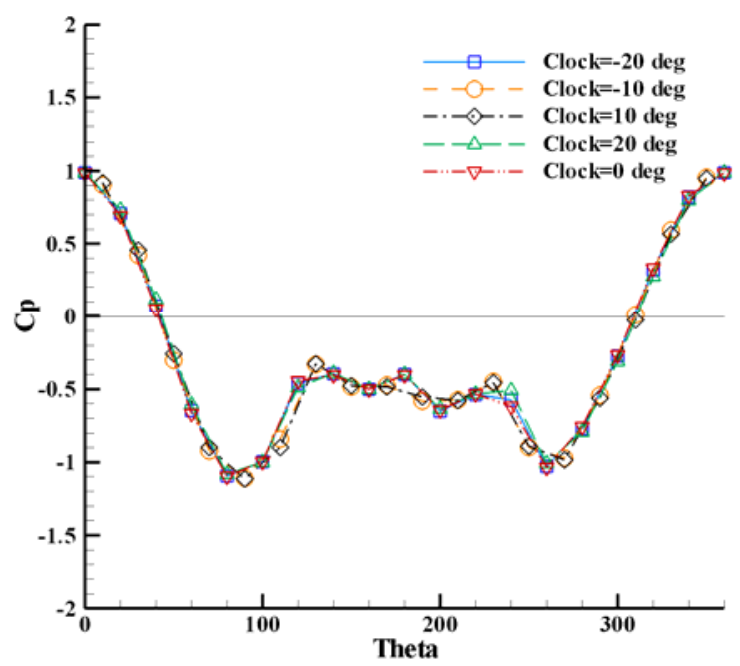

Figure 4b. Azimuthal variation of static $\mathrm{Cp}$ on starboard wheel - partially-dressed cavity closed (PDCC) configuration, $M=\mathbf{0 . 1 6 6}$.

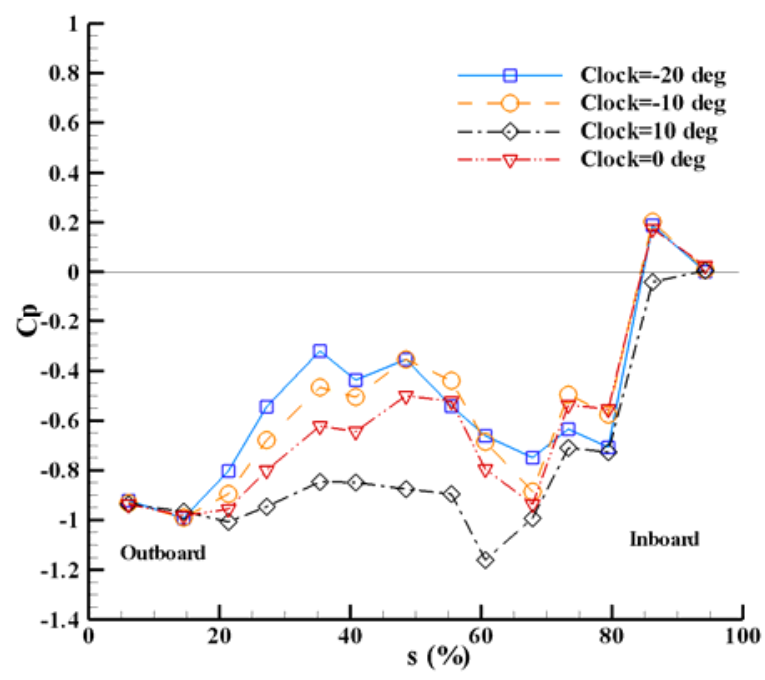

Figure 5b. Radial variation of static $\mathrm{Cp}$ along port wheel, $237^{\circ}$ arm- $P D C C$ configuration, $M=0.166$. 


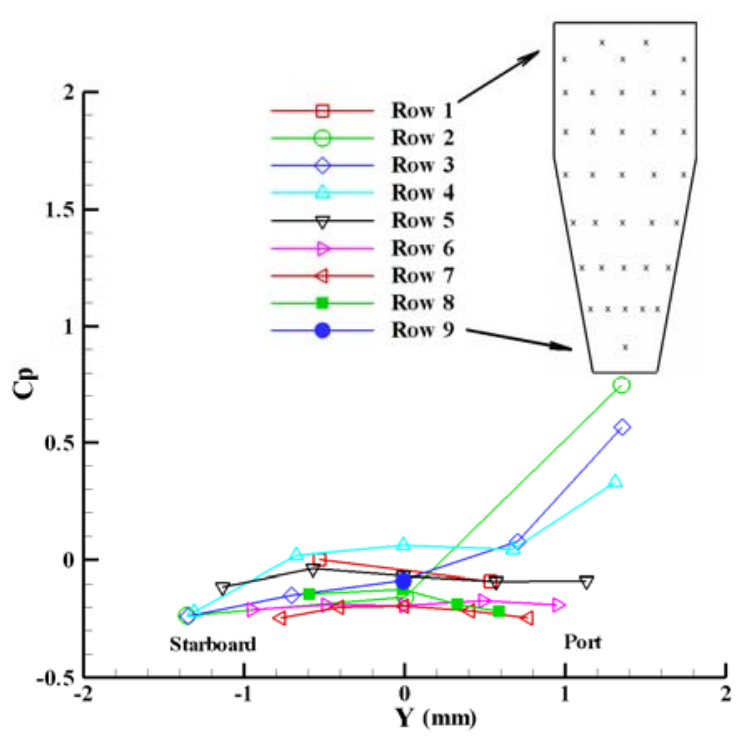

Figure 6a. Static Cp variation along upstream door surface, top to bottom (1-9)- FDCO configuration, $\mathrm{M}=\mathbf{0 . 1 6 6}$.

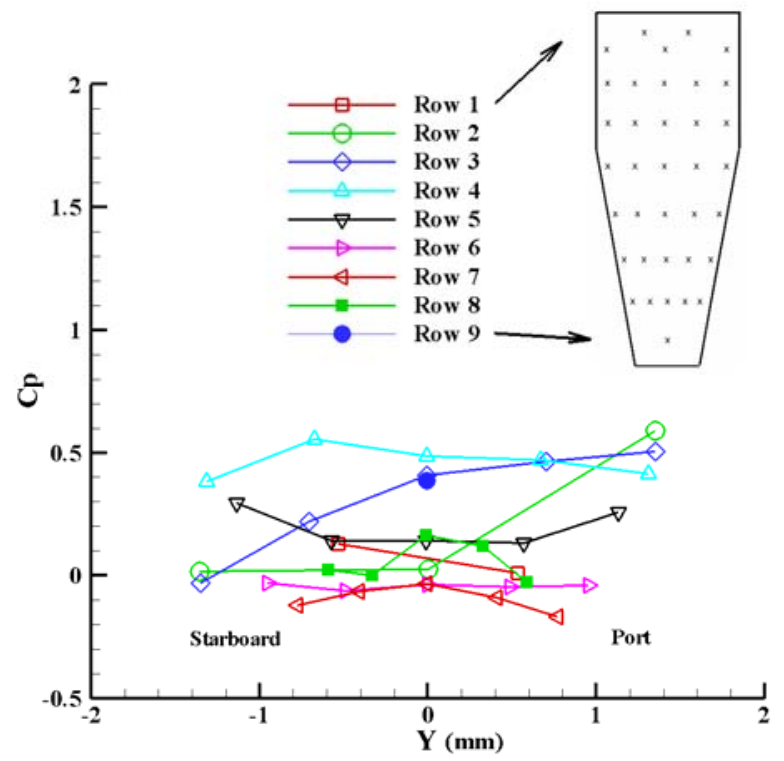

Figure 6b. Static Cp variation along upstream door surface, top to bottom (1-9)- PDCC configuration, $M=0.166$.

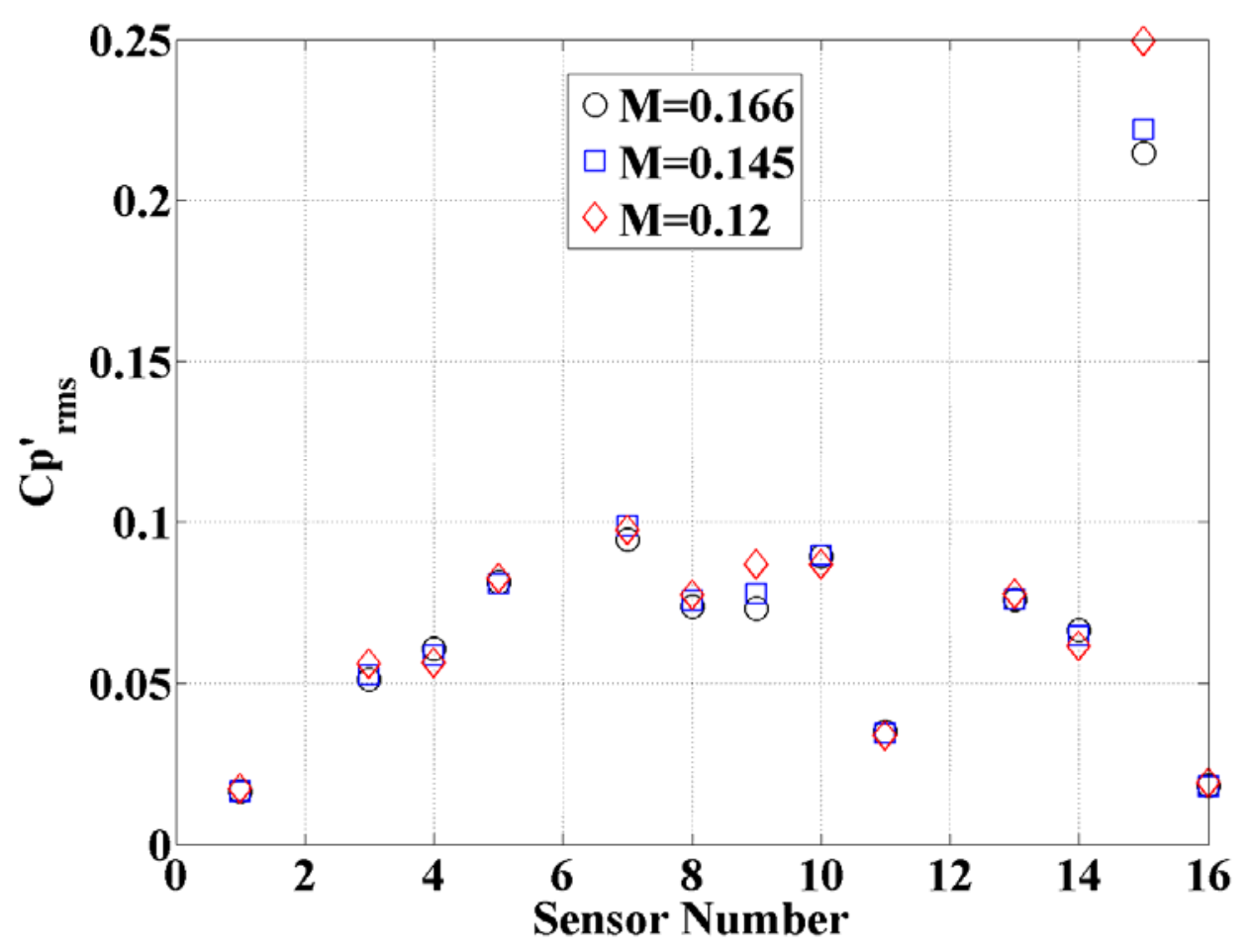

Figure 7. Coefficient of RMS unsteady pressure - FDCO configuration. 


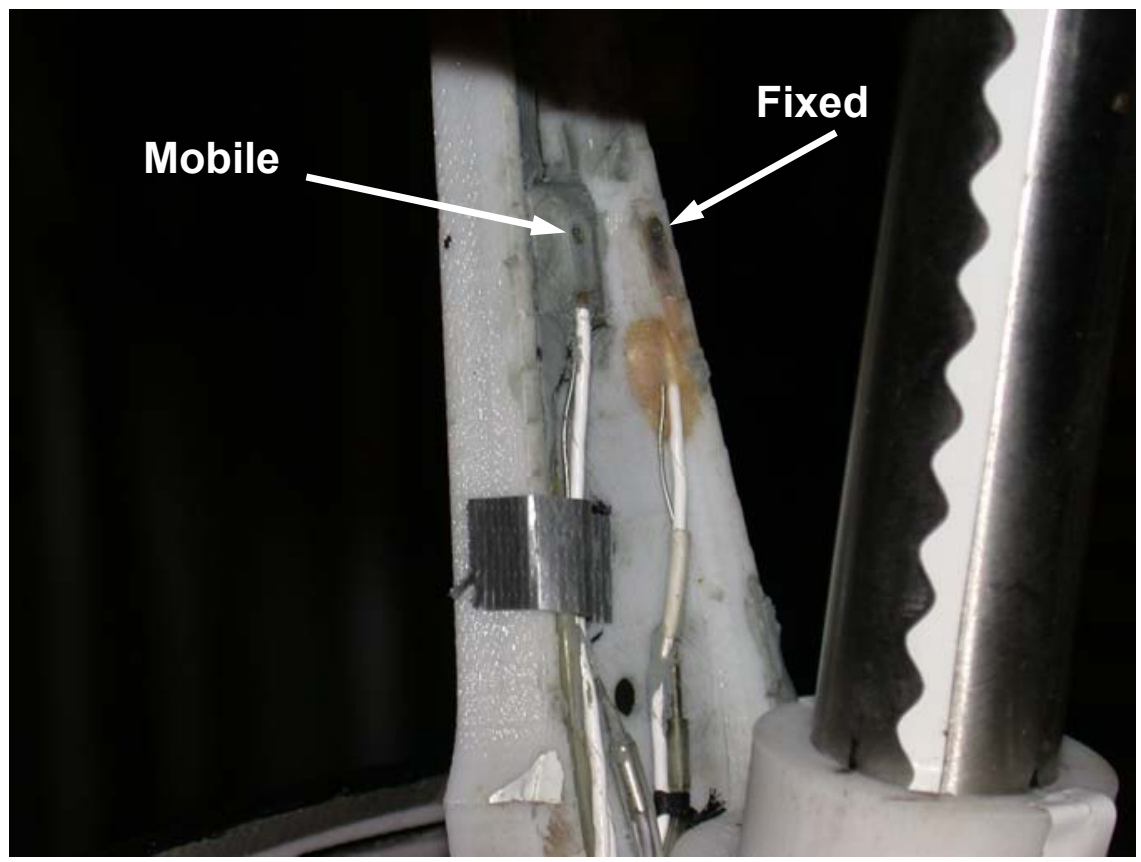

Figure 8. Torque arm with fixed (sensor 15) and mobile unsteady pressure transducers (top right and top middle, respectively, over the portion of the torque arm included in the picture).

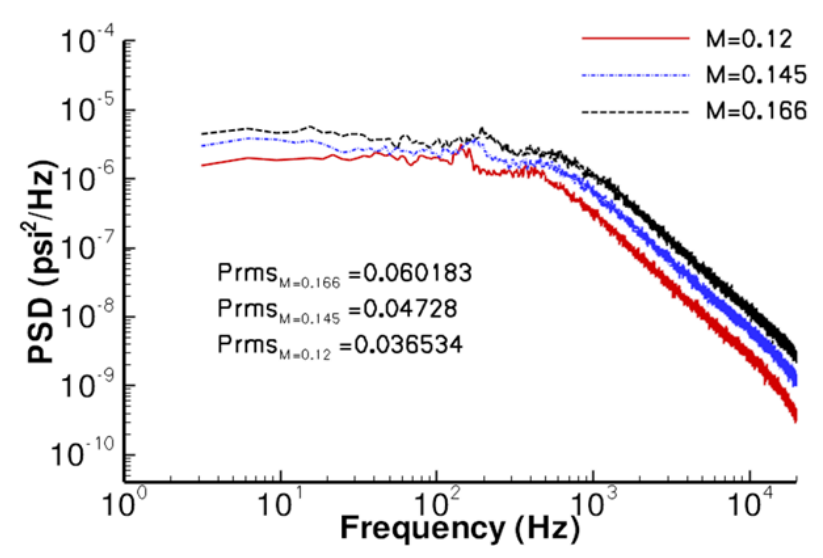

a) Variation with speed

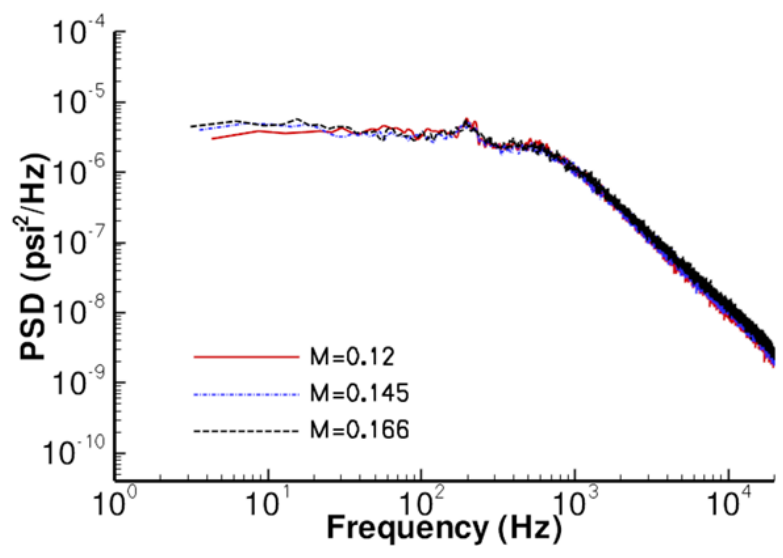

b) Normalized

Figure 9. Unsteady pressure spectra measured by transducer on torque arm behind shock strut at selected flow speeds - FDCO configuration. Spectral cutoff at $20 \mathrm{kHz}$ indicates upper bound on analysis frequency bandwidth. 


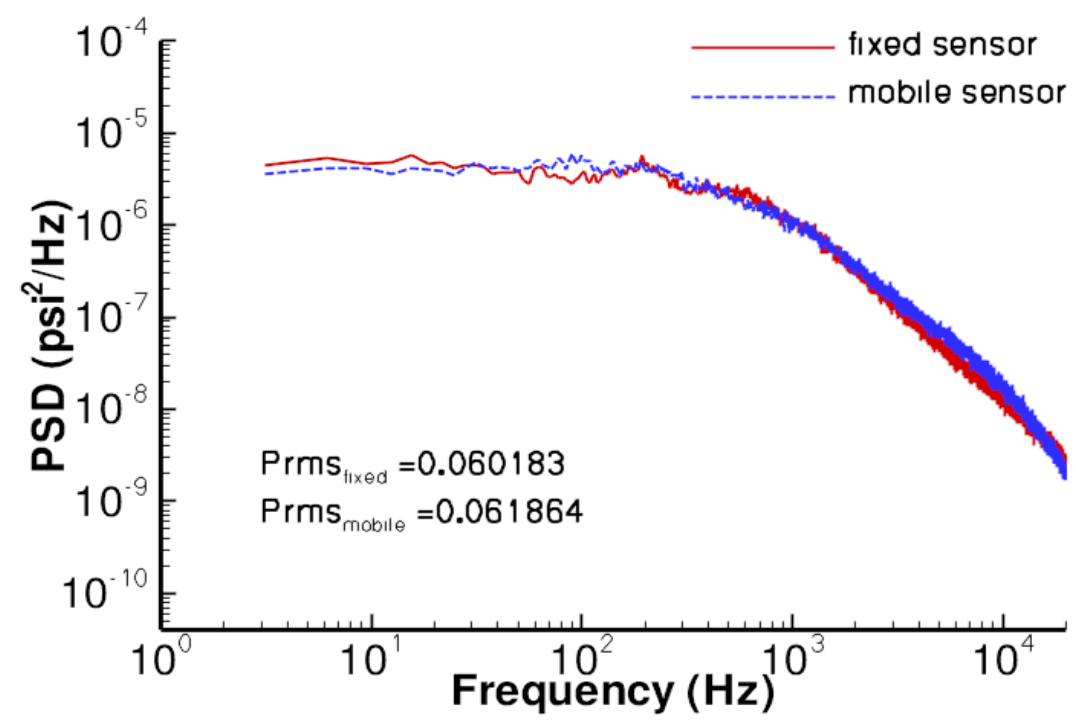

Figure 10. Unsteady pressure spectra measured by transducer on torque arm behind shock strut - fixed and mobile sensor,

FDCO configuration, $M=0.166$.

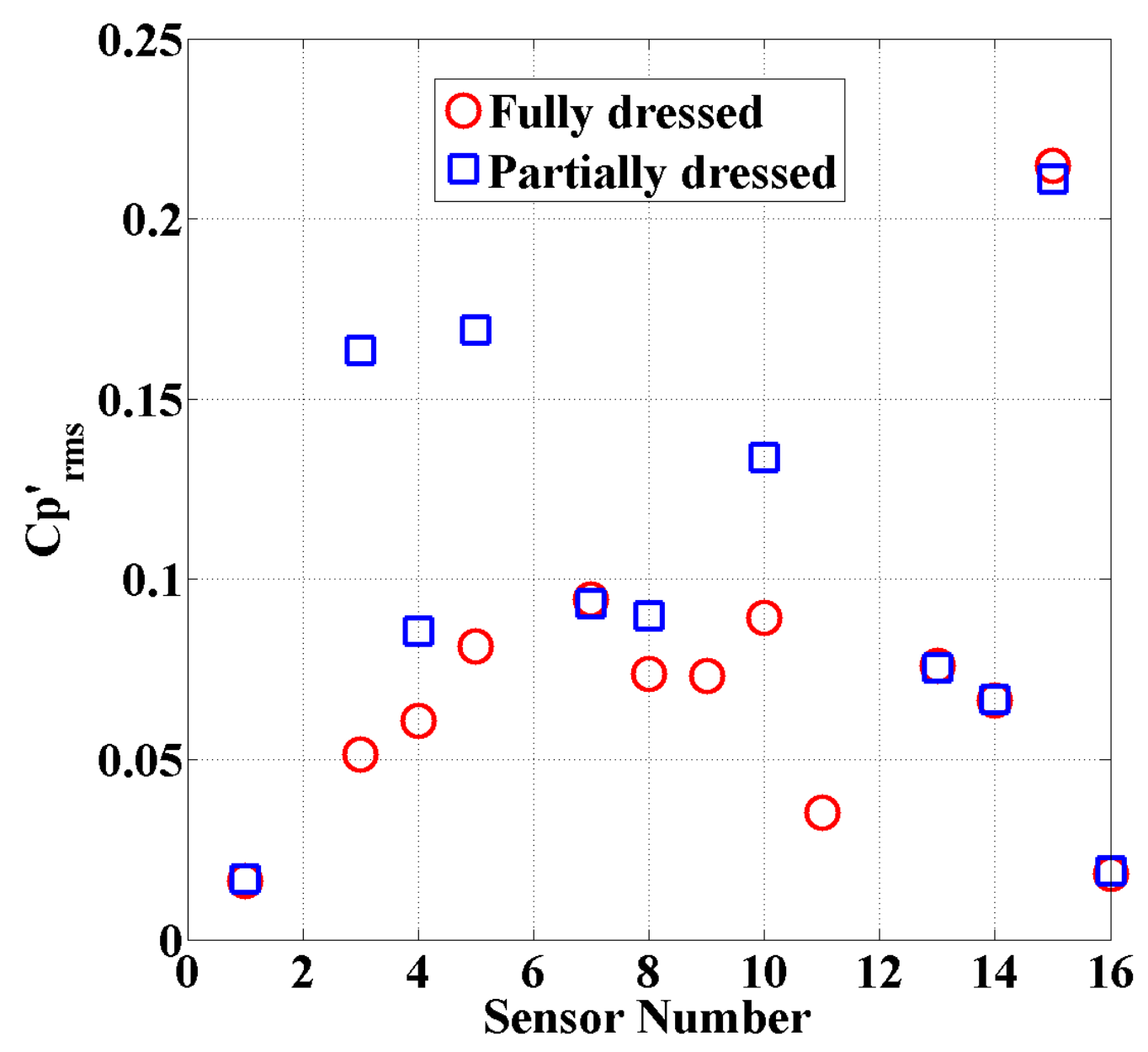

Figure 11. Coefficient of RMS unsteady pressure - FDCO vs PDCC configuration, $M=0.166$. 


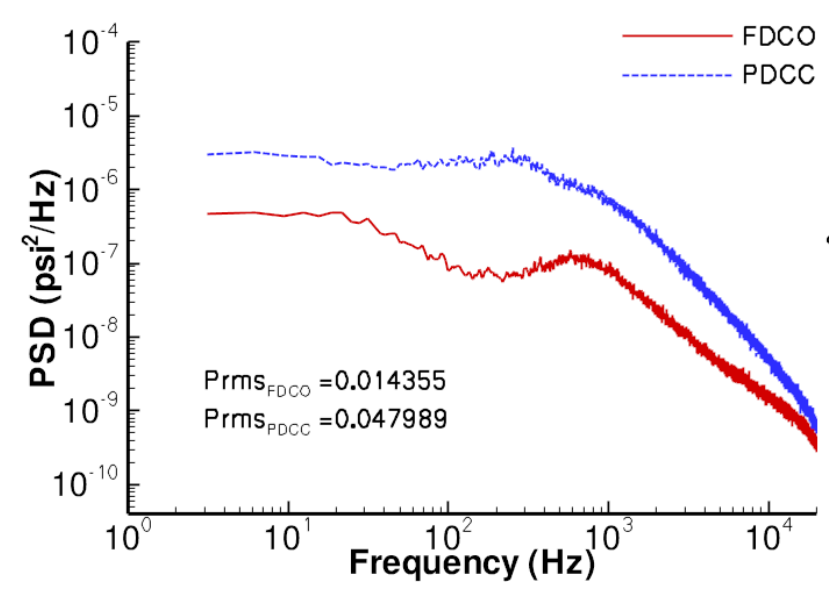

a) upper transducer on door, sensor 3

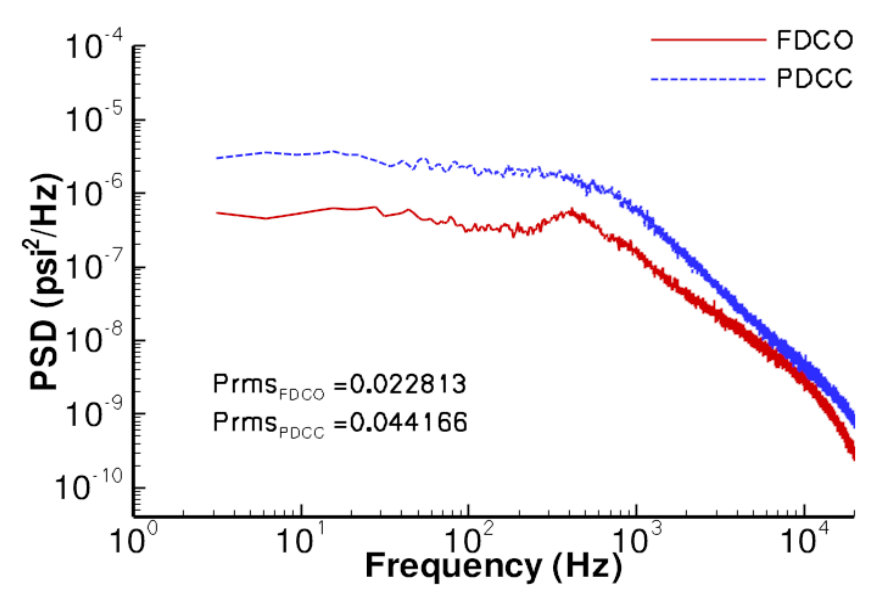

c) upper transducer on drag brace, sensor 5

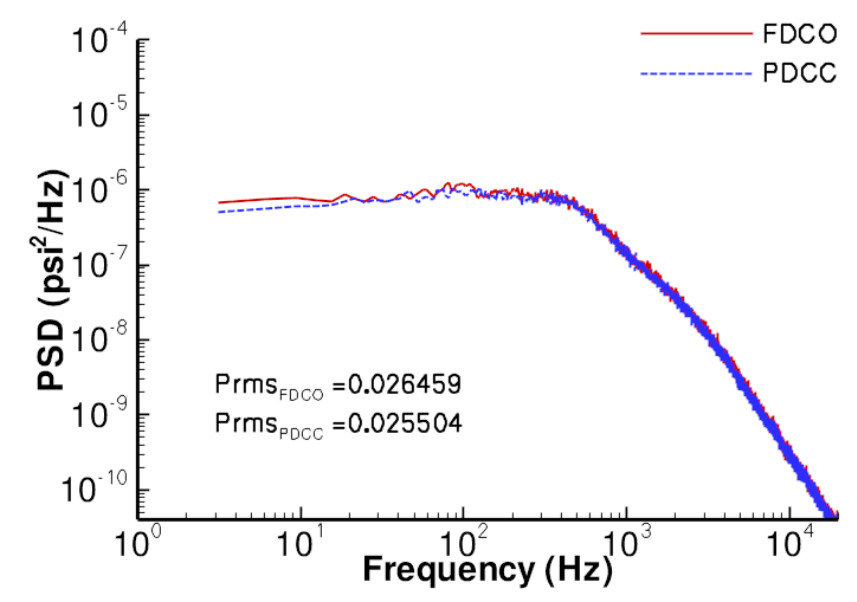

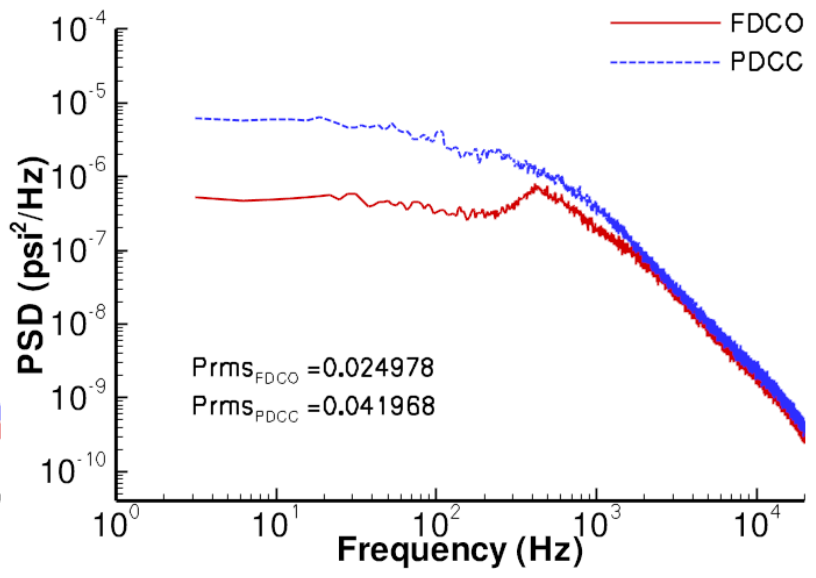

b) lower transducer on door, sensor 10

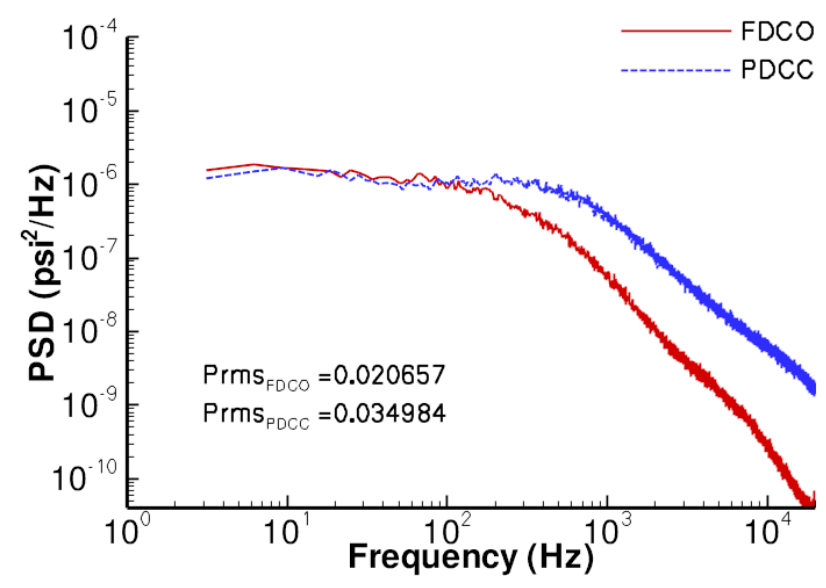

d) lower transducer on drag brace, sensor 8

e) transducer on back wall of wheel hub cavity, sensor 7

Figure 12. Unsteady surface pressure spectra for FDCO and PDCC configurations, M=0.166. 


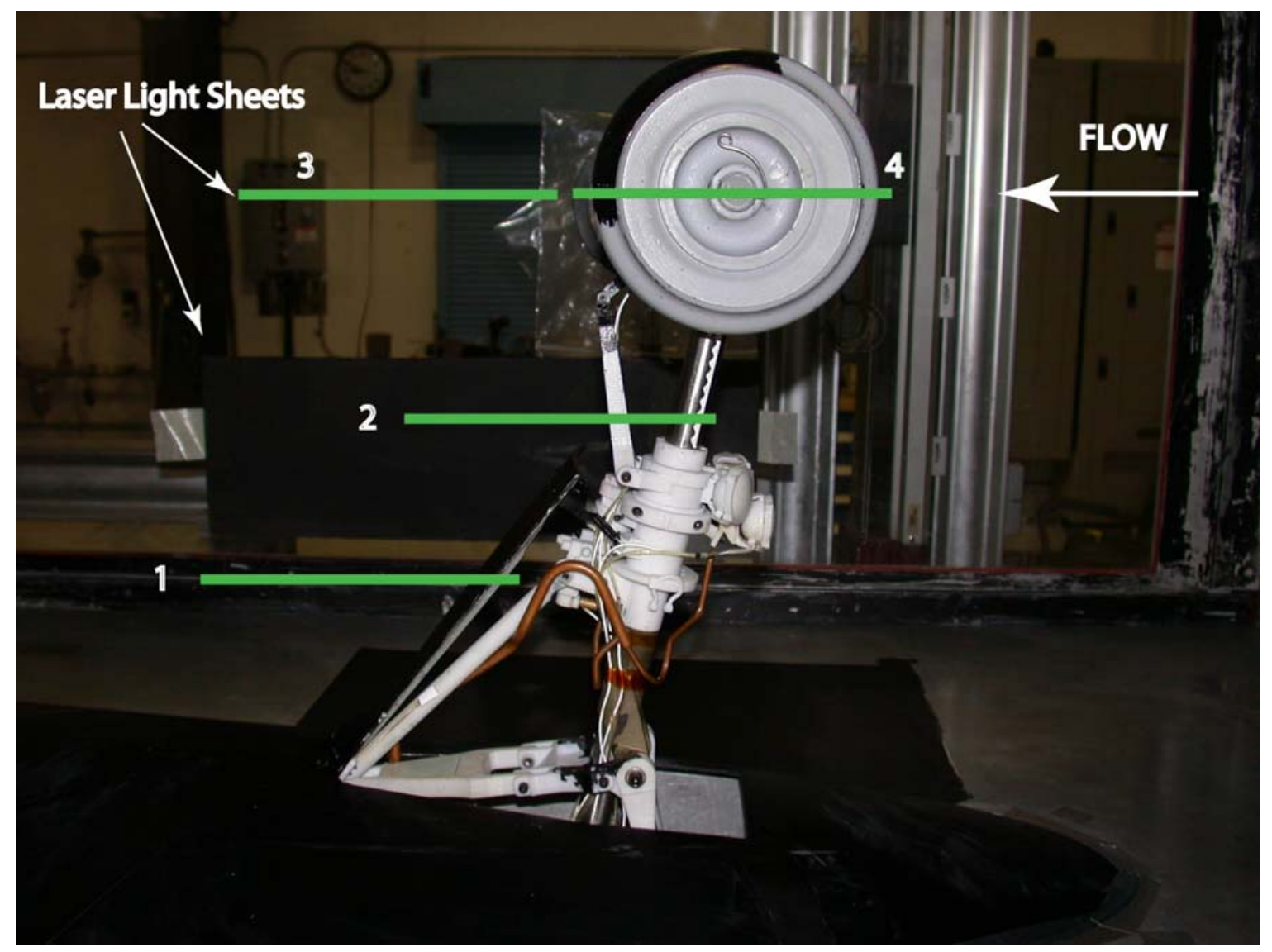

Figure 13. Locations of laser sheets for PIV measurements.

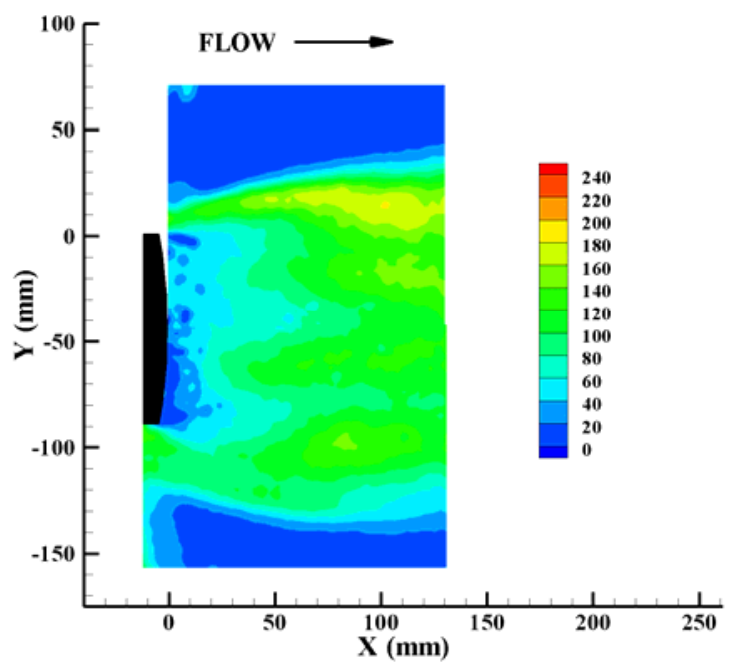

Figure 14a. Turbulent kinetic energy within wake region behind door, plane 1 - FDCO configuration, $M=0.166$.

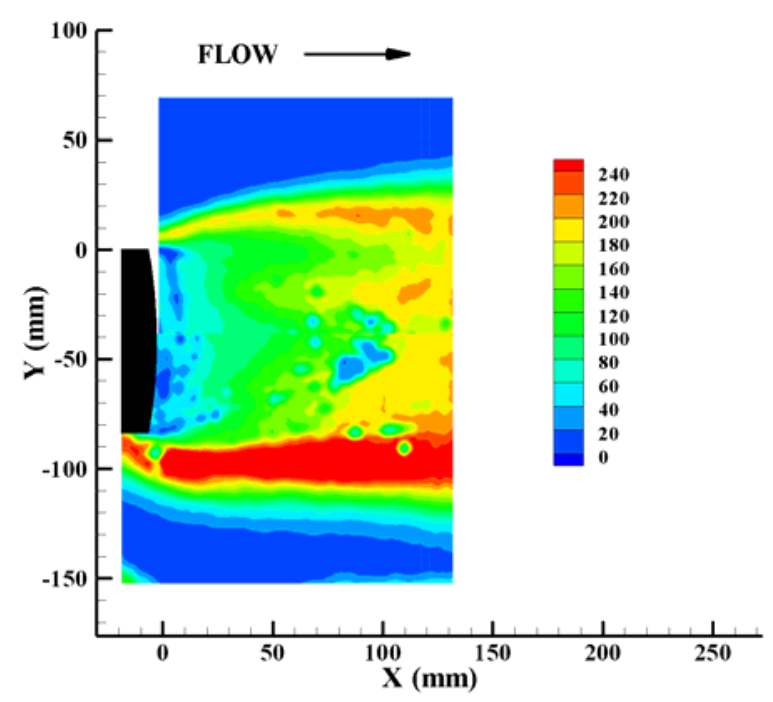

Figure 14b. Turbulent kinetic energy within wake region behind door, plane 1 - PDCC configuration, $M=0.166$. 


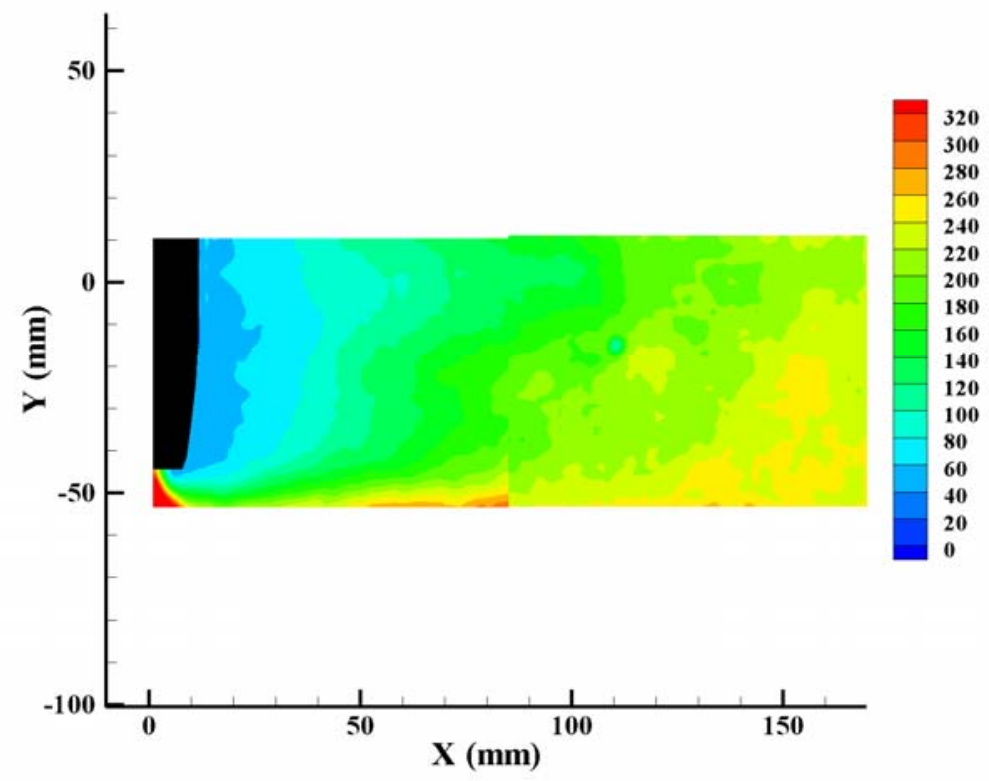

Figure 14c. Turbulent kinetic energy within wake region behind door, plane 1- PDCC configuration, $M=0.166$. (Previous entry, 2007)

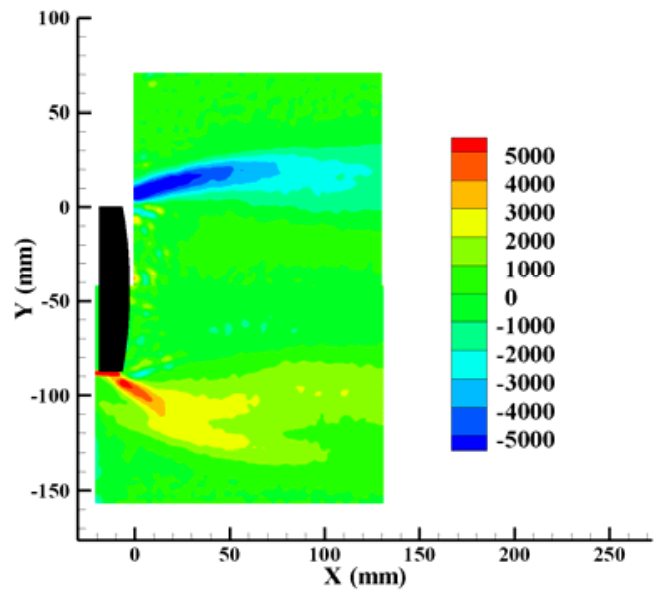

Figure 14d. Vorticity within wake region behind door, plane 1 - FDCO configuration, $M=0.166$.

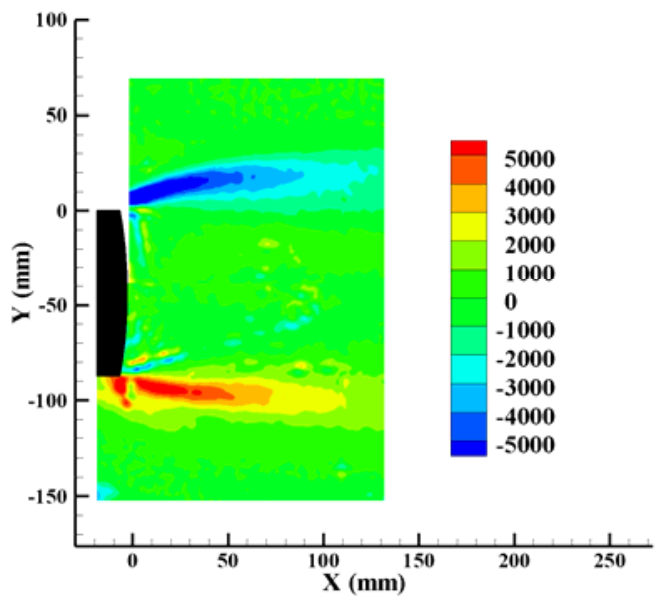

Figure 14e. Vorticity within wake region behind door, plane 1 - $P D C C$ configuration, $M=0.166$. 


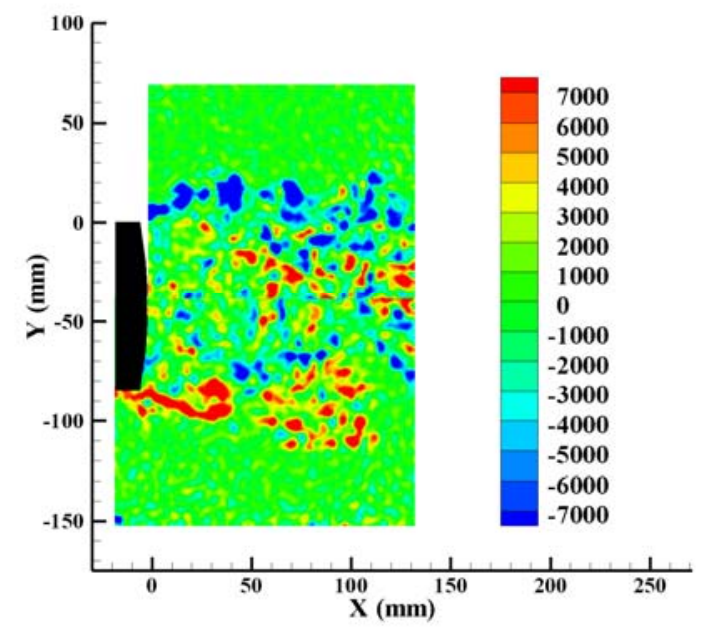

Figure 14f. Instantaneous vorticity within wake region behind door, plane 1 - PDCC configuration, M=0.166.

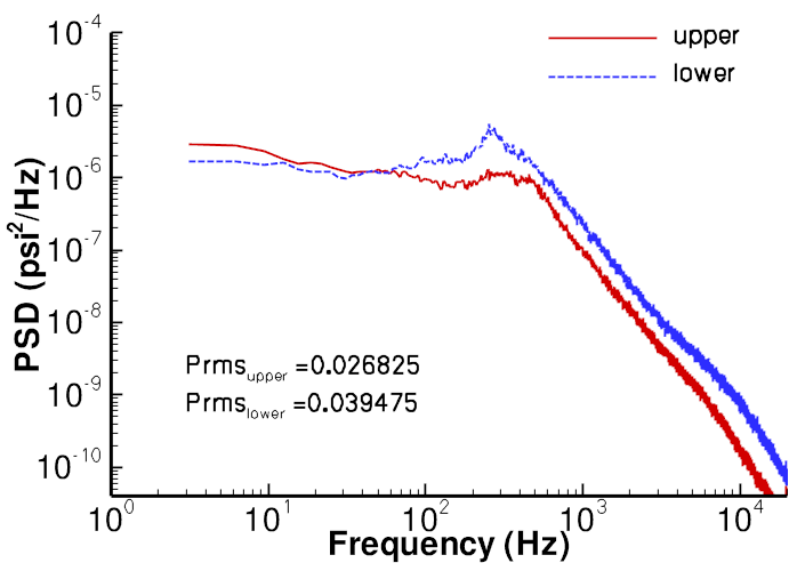

Figure 15. Power spectral density for sensors on back side of starboard door - PDCC configuration, $M=0.166$.

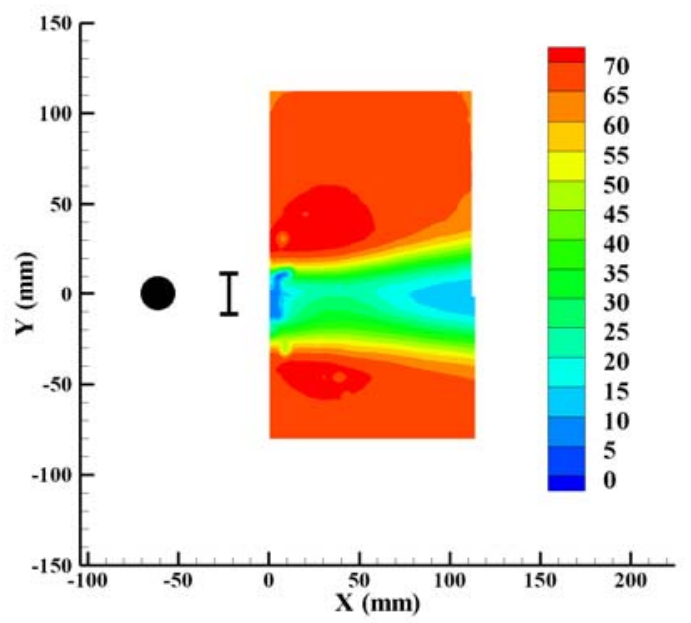

Figure 16b. Mean streamwise velocity within wake region behind torque arm, plane 2 - PDCC configuration, $\mathrm{M}=\mathbf{0 . 1 6 6 .}$ 


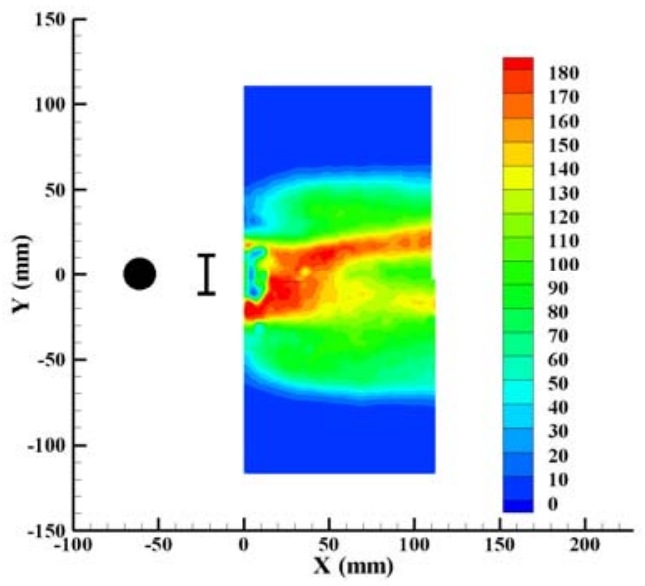

Figure 16c. Turbulent kinetic energy within wake region behind torque arm, plane 2 - FDCO configuration, $M=\mathbf{0 . 1 6 6}$.

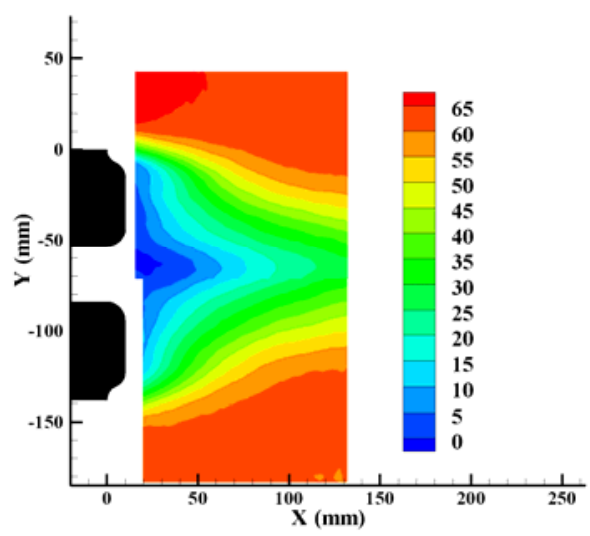

Figure 17a. Mean streamwise velocity within wake region behind wheels, plane 3 - FDCO configuration, $\mathrm{M}=\mathbf{0 . 1 6 6 .}$

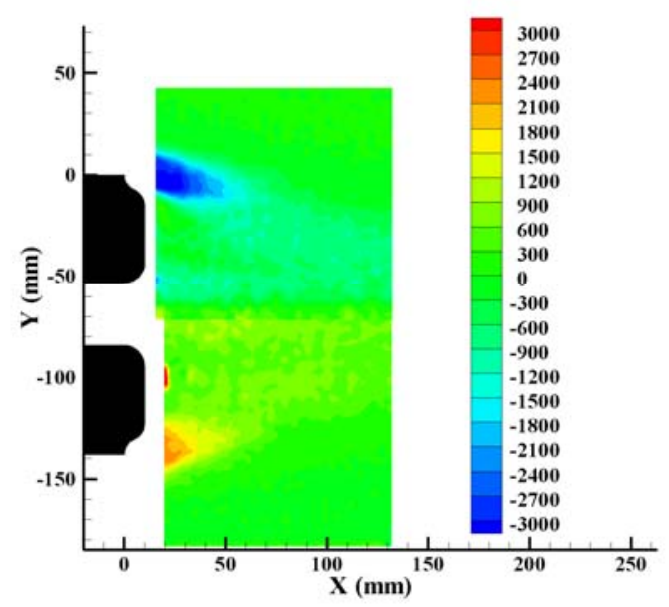

Figure 17c. Vorticity within wake region behind wheels, plane 3 - FDCO configuration, $M=0.166$.

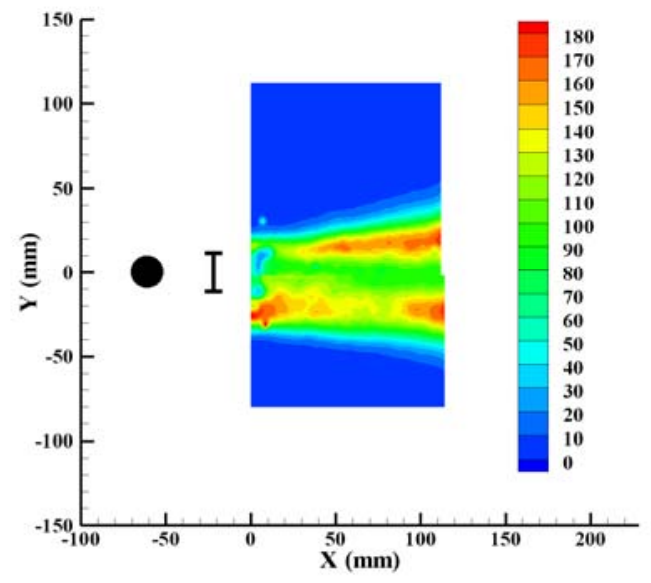

Figure 16d. Turbulent kinetic energy within wake region behind torque arm, plane 2 - PDCC configuration, $\mathrm{M}=\mathbf{0 . 1 6 6 .}$

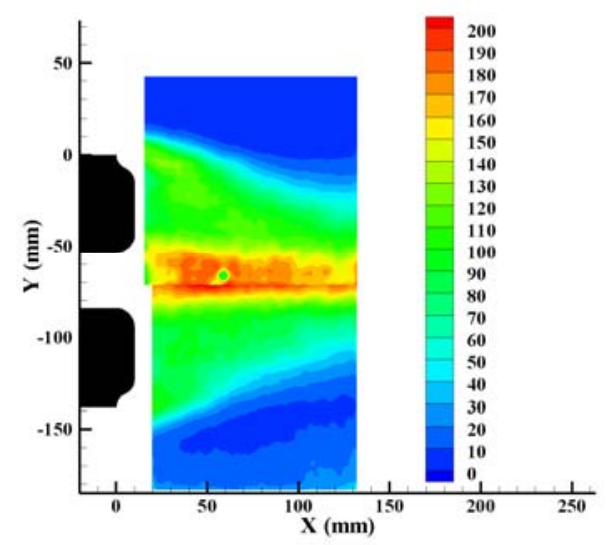

Figure 17b. Turbulent kinetic energy within wake region behind torque arm, plane 3 - FDCO configuration,

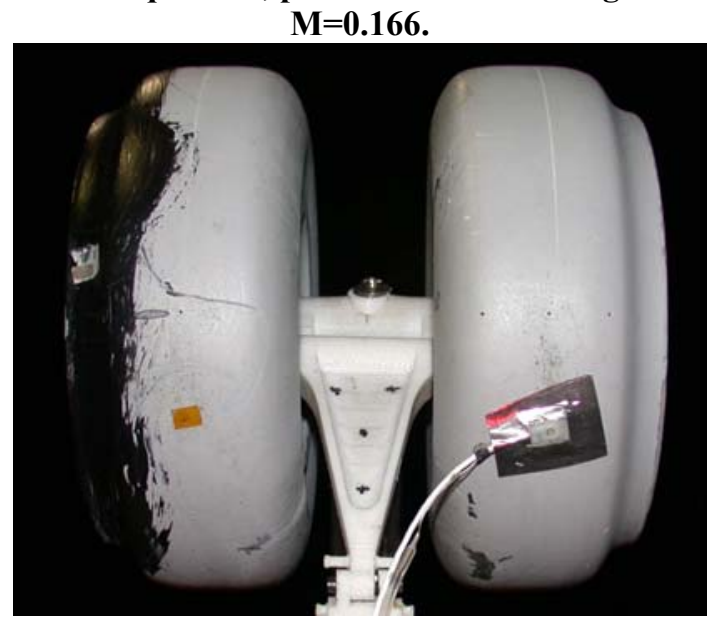

Figure 17d. Rear view of torque arm-axle connection. 


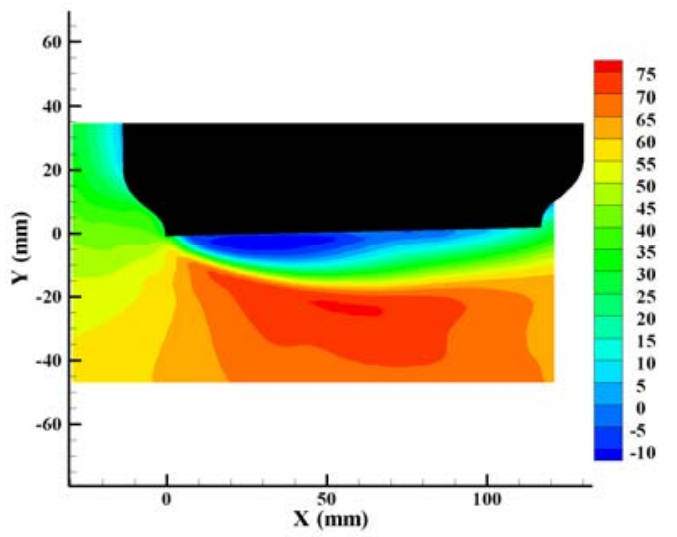

Figure 18a. Mean streamwise velocity outboard of starboard wheel, plane 4 - FDCO configuration, $\mathrm{M}=\mathbf{0 . 1 6 6}$.

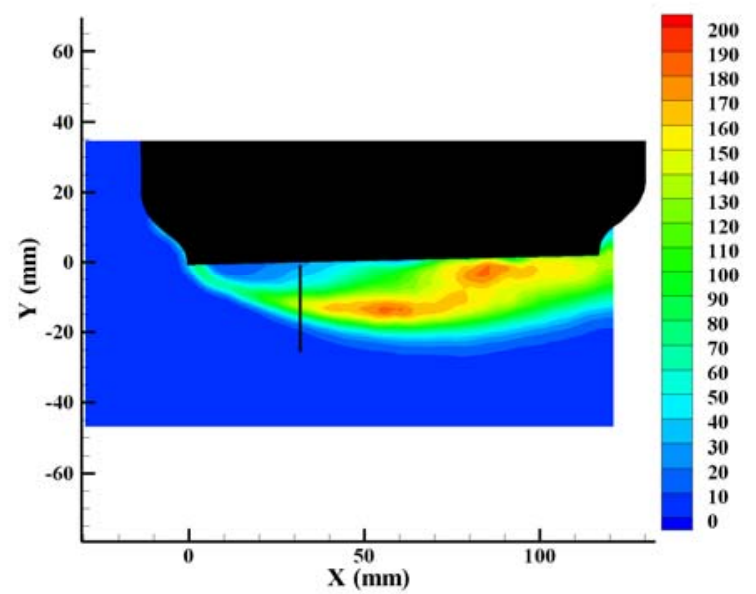

Figure 18c. Turbulent kinetic energy outboard of starboard wheel, plane 4 - FDCO configuration, $\mathrm{M}=\mathbf{0 . 1 6 6}$.

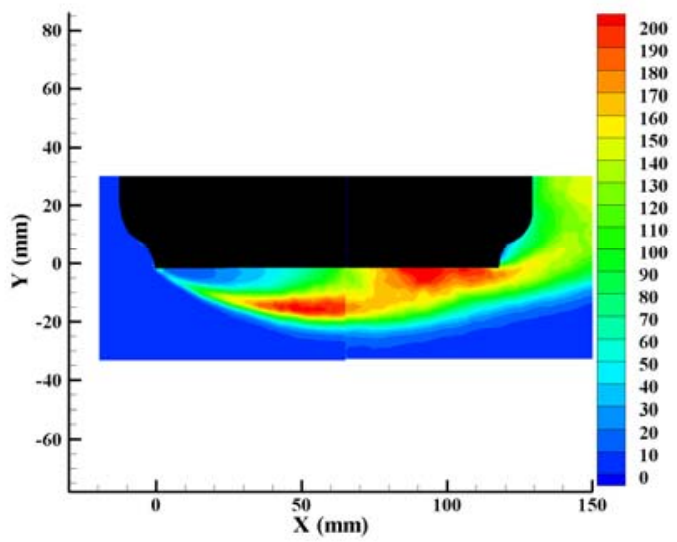

Figure 18e. Turbulent kinetic energy outboard of starboard wheel, plane 4 - FDCO configuration, (Previous entry, 2007), $M=0.166$.

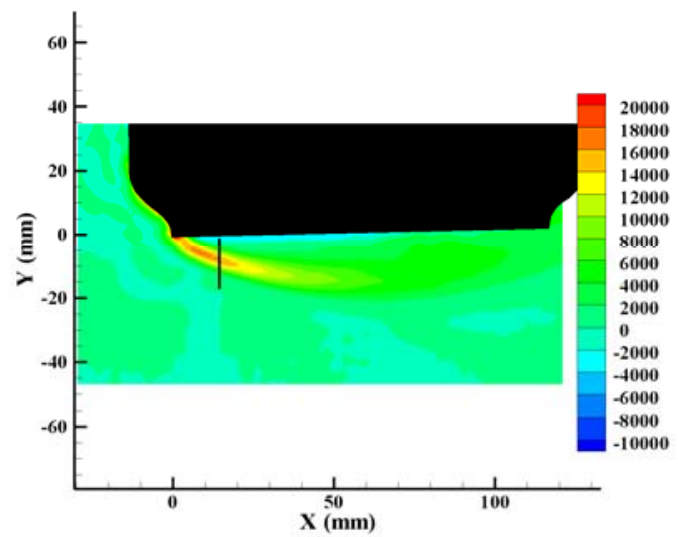

Figure 18b. Vorticity outboard of starboard wheel, plane $4-$ FDCO configuration, $M=0.166$.

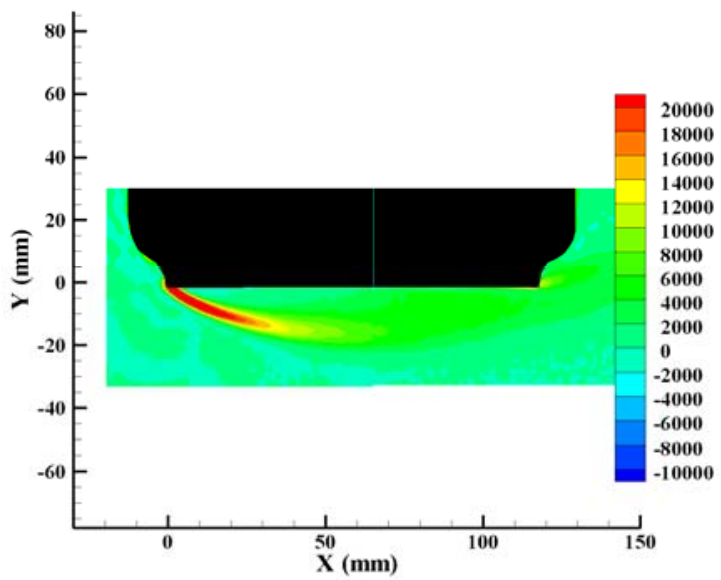

Figure 18d. Vorticity outboard of starboard wheel, plane 4 - FDCO configuration, (Previous entry, 2007), $M=0.166$.

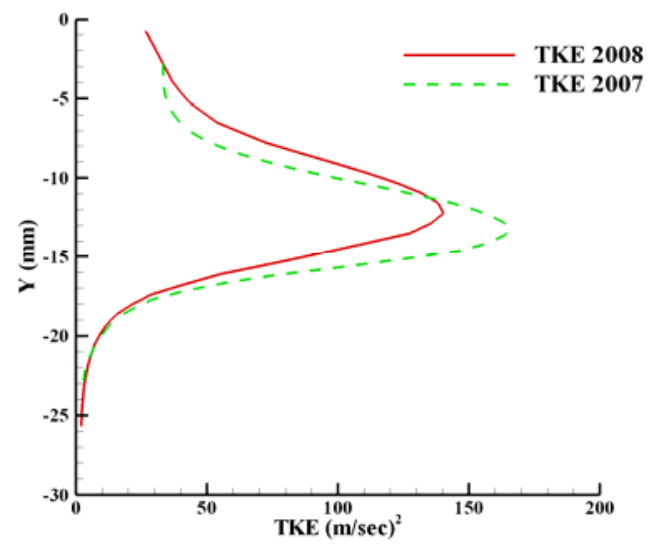

Figure 19a. TKE profiles outboard of starboard wheel, plane 4 - FDCO configuration, $M=0.166$. 


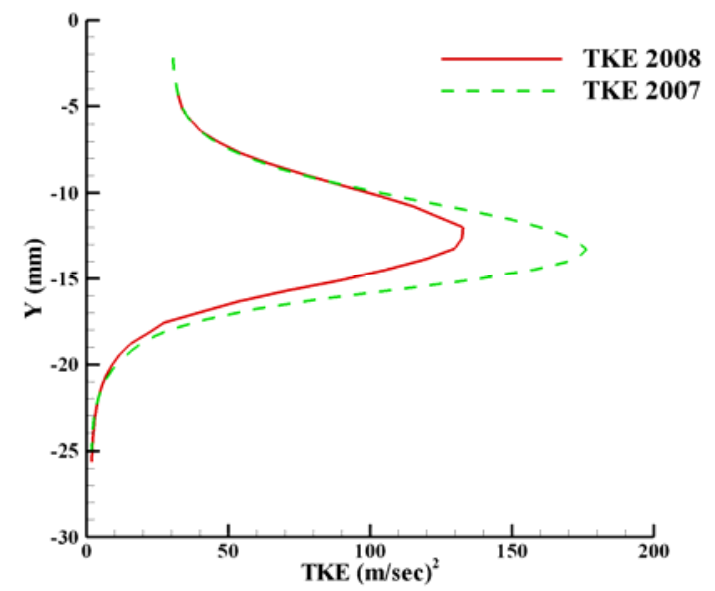

Figure 19b. TKE profiles outboard of starboard wheel, plane 4 - $P D C C$ configuration, $M=0.166$.

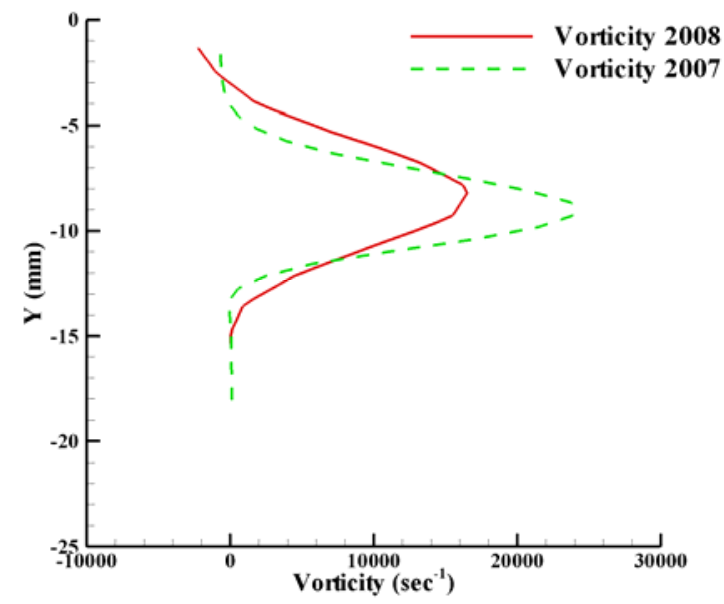

Figure 19d. Vorticity profiles outboard of starboard wheel, plane 4 - PDCC configuration, cavity open, $\mathrm{M}=\mathbf{0 . 1 6 6 .}$

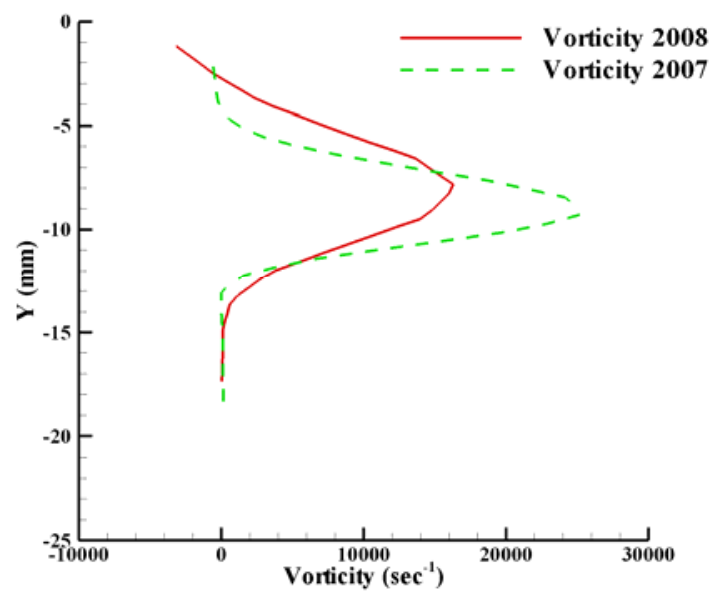

Figure 19c. Vorticity profiles outboard of starboard wheel, plane 4 - FDCO configuration, $M=0.166$.

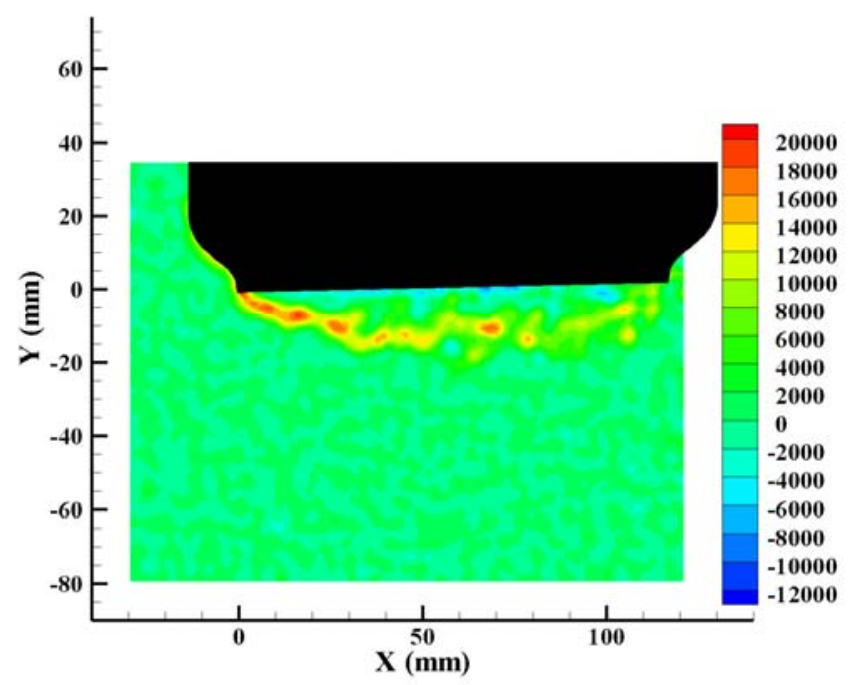

Figure 20. Instantaneous vorticity outboard of starboard wheel, plane 4 - FDCO configuration, $M=0.166$. 